\title{
Using Time Series of High-Resolution Planet Satellite Images to Monitor Grapevine Stem Water Potential in Commercial Vineyards
}

\author{
David Helman $1,2, * \mathbb{E}$, Idan Bahat ${ }^{1,3}$, Yishai Netzer ${ }^{4,5}$, Alon Ben-Gal ${ }^{6} \mathbb{D}$, Victor Alchanatis ${ }^{1}{ }^{(\mathbb{D}}$, \\ Aviva Peeters ${ }^{7}$ and Yafit Cohen ${ }^{1}$ (D) \\ 1 Institute of Agricultural Engineering, Agricultural Research Organization (Volcani Center), P.O. Box 15159, \\ Rishon LeZion 7505101, Israel; idanba1@gmail.com (I.B.); victor@volcani.agri.gov.il (V.A.); \\ yafitush@volcani.agri.gov.il (Y.C.) \\ 2 Department of Geography and the Environment, Bar-Ilan University, Ramat Gan 5290002, Israel \\ 3 Institute of Plant Sciences and Genetics in Agriculture, The Robert H. Smith Faculty of Agriculture, \\ Food \& Environment, The Hebrew University of Jerusalem, Rehovot 76100, Israel \\ 4 Department of Agriculture and Oenology, Eastern R\&D Center, Ariel 40700, Israel; ynetzer@gmail.com \\ 5 Department of Chemistry \& Biotech Engineering, Ariel University, Ariel 40700, Israel \\ 6 Department of Soil, Water and Environmental Sciences, Agricultural Research Organization Gilat Research \\ Center, Mobile post Negev, Gilat 8531100, Israel; bengal@volcani.agri.gov.il \\ 7 TerraVision Lab, Midreshet Ben-Gurion 8499000, Israel; aviva@terravisionlab.com \\ * Correspondence: davidhelman.biu@gmail.com or david.helman@biu.ac.il; Tel.: +972-3-531-8342
}

Received: 1 August 2018; Accepted: 9 October 2018; Published: 11 October 2018

\begin{abstract}
Spectral-based vegetation indices (VI) have been shown to be good proxies of grapevine stem water potential $\left(\Psi_{\text {stem }}\right)$, assisting in irrigation decision-making for commercial vineyards. However, VI- $\Psi_{\text {stem }}$ correlations are mostly reported at the leaf or canopy scales, using proximal canopy-based sensors or very-high-spatial resolution images derived from sensors mounted on small airplanes or drones. Here, for the first time, we take advantage of high-spatial resolution (3-m) near-daily images acquired from Planet's nano-satellite constellation to derive VI- $\Psi_{\text {stem }}$ correlations at the vineyard scale. Weekly $\Psi_{\text {stem }}$ was measured along the growing season of 2017 in six vines each in 81 commercial vineyards and in 60 pairs of grapevines in a 2.4 ha experimental vineyard in Israel. The Clip application programming interface (API), provided by Planet, and the Google Earth Engine platform were used to derive spatially continuous time series of four VIs-GNDVI, NDVI, EVI and SAVI—in the 82 vineyards. Results show that per-week multivariable linear models using variables extracted from VI time series successfully tracked spatial variations in $\Psi_{\text {stem }}$ across the experimental vineyard (Pearson's- $r=0.45-0.84 ; \mathrm{N}=60$ ). A simple linear regression model enabled monitoring seasonal changes in $\Psi_{\text {stem }}$ along the growing season in the vineyard $(r=0.80-0.82)$. Planet VIs and seasonal $\Psi_{\text {stem }}$ data from the 82 vineyards were used to derive a 'global' model for in-season monitoring of $\Psi_{\text {stem }}$ at the vineyard-level $(r=0.78$; RMSE $=18.5 \%$; $\mathrm{N}=970)$. The 'global' model, which requires only a few VI variables extracted from Planet images, may be used for real-time weekly assessment of $\Psi_{\text {stem }}$ in Mediterranean vineyards, substantially improving the efficiency of conventional in-field monitoring efforts.
\end{abstract}

Keywords: Google Earth Engine; grapevine; irrigation; Planet; time series; stem water potential; VI; vineyard

\section{Introduction}

Deficit irrigation is a commonly used irrigation strategy in vineyards aiming to achieve high-quality berries for premium wine production [1]. However, to optimize grape quality and 
production deficit, irrigation should be properly controlled. Proper irrigation management is also compulsory to achieve uniform quality of berries across the vineyard area. An effective method to guide irrigation management of wine grapes is continuous spatial (across the vineyard) and temporal (along the season) monitoring of grapevine water status [2]. Water status is typically quantified by measuring vine stem water potential $\left(\Psi_{\text {stem }}\right)$, which provides an indication of the impact of soil water content on grapevine water status [3]. To achieve an accurate picture of the water status variability across the entire vineyard area, continuous $\Psi_{\text {stem }}$ measurements are required from as many vines as possible. This task requires substantial human resources, making it time consuming.

Emerging precision agriculture tools such as proximal and remote sensing offer possible replacement, or at least support, of conventional in-field monitoring techniques $[4,5]$. Proximal and remote sensing tools may be used to provide the required information for irrigation management control [6], as well as to allow spatial consideration of irrigation needs across the crop field [7]. Remote and proximal sensing have been used for monitoring vegetation dynamics [8] and processes including water status [9-11], plant nutrient content [12,13], plant diseases [14,15] and crop phenotyping [16]. The information received from sensors mounted on drones or small airplanes can be applied to develop site-specific irrigation and other management decisions [17]. Thermal sensors mounted on airplanes or drones may provide information on plant water status through the use of the crop water stress index [18-20]. Crop water stress index (CWSI), which is based on crop canopy temperature [21], has been recognized as a reliable index for monitoring in-field water status variability within a vineyard area [22-25]. CWSI has been shown to correlate with $\Psi_{\text {stem, }}$ though typically displaying different correlations for different dates along the season [26,27].

Another approach is to use vegetation indices (VIs) derived from spectral bands as proxies for water status parameters and/or yield production. For example, Espinoza et al. [28], found that the normalized difference vegetation index (NDVI) and the green normalized difference vegetation index (GNDVI) derived from very-high-spatial resolution images $(2.6 \mathrm{~cm})$ were both correlated with pre-harvest leaf stomatal conductance $\left(g_{s} ; r=0.56\right.$ and 0.65 , respectively) and yield production $(r=0.68$ and 0.73 , respectively) in a cabernet sauvignon vineyard near Benton City, Washington. Baluja et al. [22] found strong correlations of spectral-based vegetation indices such as, GNDVI, NDVI and the modified simple ratio (MSR) with $g_{s}\left(r=0.84,0.87\right.$ and 0.88 , respectively) and $\Psi_{\text {stem }}$ $(r=0.76,0.82$ and 0.81 , respectively) using images acquired from an unmanned aerial vehicle in a commercial rain-fed tempranillo vineyard in Spain. Their results imply that VIs can serve as good water stress indicators in vineyards when using very-high-spatial resolution images $(10 \mathrm{~cm})$ that allow the extraction of pure canopy pixels. As expected, they also found high correlations of thermal data with $g_{s}$ and $\Psi_{\text {stem; }}$ however, the correlation changed along the season [22], meaning that a per-date calibration should be derived in order to provide recommendations for irrigation scheduling throughout the season.

Zarco-Tejada et al. [29] proposed a normalized photochemical reflectance index ( $\mathrm{PRI}_{\text {norm }}$ ) using a combination of the re-normalized difference vegetation index (RDVI), which is sensitive to canopy structure, and a red edge index, sensitive to chlorophyll content (R700/R670), to detect xanthophyll pigment changes and normalize for leaf area and chlorophyll content level reduction induced by water stress. They found that PRI $\mathrm{I}_{\text {norm }}$ was highly correlated with midday $g_{s}(r=0.89)$ and leaf water potential ( $\left.\Psi_{\text {Leaf }} ; r=0.88\right)$ in an experimental pinot noir vineyard in California. Lower correlations were also obtained with original PRI ( $r=0.72$ and 0.7 , respectively) and NDVI ( $r=0.57$ and 0.62 , respectively) [29]. Using leaf-level spectroradiometer measurements, Rodríguez et al. [30] and Maimaitiyiming et al. [31] showed that water status parameters such as equivalent water thickness (EWT), $\Psi_{\text {Leaf }}, \Psi_{\text {stem }}$ and $g_{s}$ can be derived from spectral-based VIs in vineyards.

Though promising, most of these studies (including some not mentioned here) are conducted at the leaf-level or make use of sensors mounted on small airplanes or drones, offering a limited monitoring technique in terms of coverage area. The financial cost of ground or aerial sensing can 
hardly allow their application on a daily basis. Also, historically, the satellite spatial and/or temporal resolution has been too coarse for in-field water status monitoring [32].

A constellation of nano-satellites (using a large number of small compact satellites at the same time) was recently suggested to overcome this spatio-temporal limitation [33]. Planet [34] is an example of such a company operating a large number of CubeSat $3 \mathrm{U}$ form $(10 \times 10 \times 30 \mathrm{~cm})$ nano-satellites, providing daily images with 4 wavebands (RGB + NIR) at a high spatial resolution of $3 \mathrm{~m}$ since early 2016.

In this study, we make use of the high spatio-temporal resolution images provided by Planet to compare four different VIs with midday $\Psi_{\text {stem }}$ measured weekly along the growing season of 2017 in 81 commercial vineyards and in one experimental vineyard (Mevo Beitar) in Israel. We examine the use of simple regression and multivariable linear models, with several VI-based metrics extracted from the VI time series, to predict spatio-temporal variability in $\Psi_{\text {stem }}$ along the growing season. The main goal is to provide a high-resolution satellite remote sensing tool to support real-time deficit irrigation management in high-quality commercial vineyards.

\section{Materials and Methods}

\subsection{The Study Region}

Our study was undertaken over 81 commercial vineyards and one experimental vineyard in Israel during the 2017 growing season. The study targeted three regions, Judea, Upper Galilee, and Golan Heights, located in hilly areas in the central and northern parts of Israel (approximately $110 \mathrm{~km}$ apart; Figure 1a) in which grapevines are grown in small commercial vineyards for premium high-quality wine production. All of the vineyards were subjected to a Mediterranean climate, characterized by rainfall limited to the mild winter months and hot dry summers.

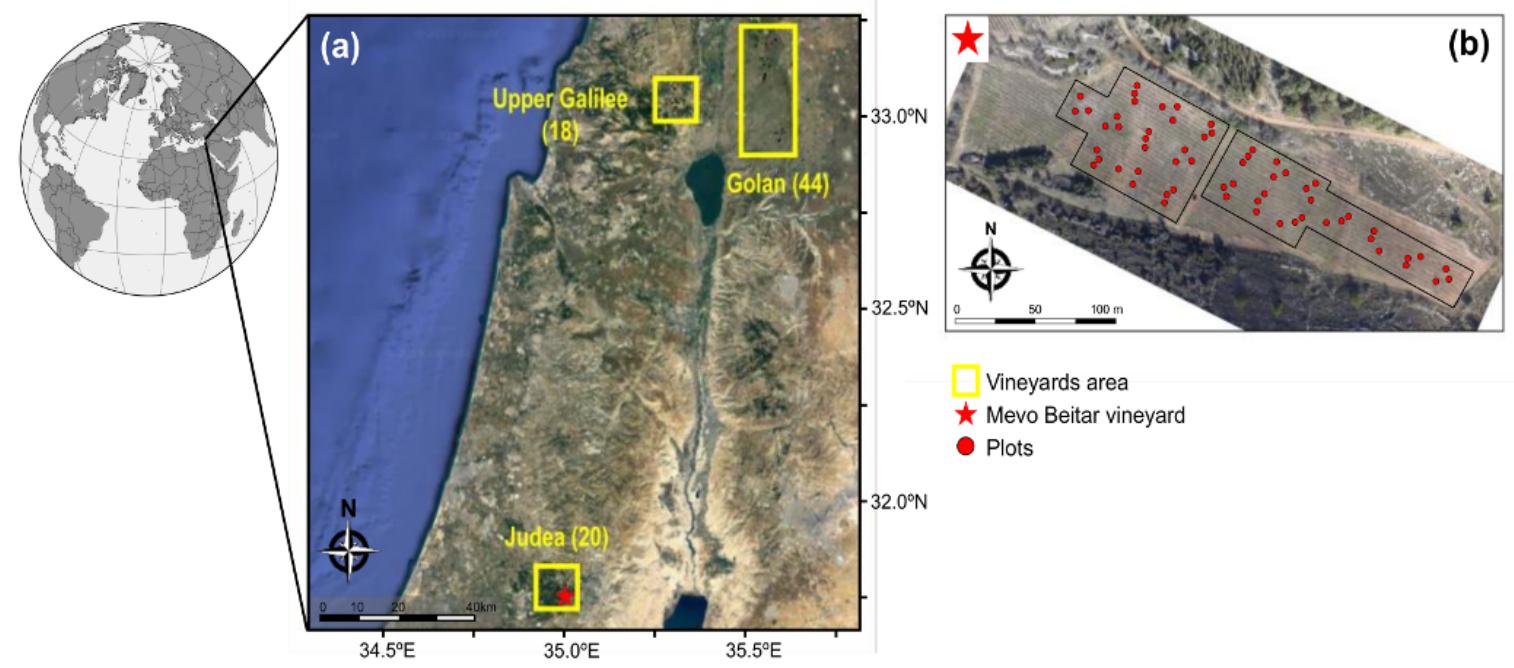

Figure 1. (a) Location of the three regions with the 82 vineyards used in this study shown on a Google Earth map, and (b) aerial photograph of the experimental vineyard at Mevo Beitar in the Judea region (location marked with a red star in (a). The 60 plots at Mevo Beitar vineyard in which stem water potential $\left(\Psi_{\text {stem }}\right)$ was measured in two grapevines per-plot along the 2017 growing season is shown in (b).

In the Golan Heights region, vineyards typically consisted of cabernet sauvignon (32\%), merlot $(16 \%)$ and other red and white species (Table A1). Located at elevations of $600-1120 \mathrm{~m}$ above sea level (m.a.s.l.), these vineyards receive a mean annual rainfall amount of $c .800 \mathrm{~mm} \mathrm{y}^{-1}$. The minimum and maximum mean air temperatures in this region during 2017 were $-5.6^{\circ} \mathrm{C}$ and $34.3^{\circ} \mathrm{C}$ for January and August, respectively. 
In the Upper Galilee, vineyards consisted of cabernet sauvignon (22\%), chardonnay (17\%) and other red and white species (Table A1), which were grown at elevations of 710-830 m.a.s.l. The mean annual rainfall amount in the Upper Galilee region is $670 \mathrm{~mm} \mathrm{y}^{-1}$, with minimum and maximum mean air temperatures of $-0.6{ }^{\circ} \mathrm{C}$ and $33.8^{\circ} \mathrm{C}$ for January and August 2017, respectively.

In the Judea region, vineyards mainly consisted of merlot (40\%), cabernet sauvignon $(22 \%)$ and other red species (Table A1). Vineyards are typically located at elevation of 600-740 m.a.s.l., receiving a mean annual rainfall amount of $c .535 \mathrm{~mm} \mathrm{y}^{-1}$. Minimum and maximum mean air temperatures in this region were $2{ }^{\circ} \mathrm{C}$ and $38.2^{\circ} \mathrm{C}$ for January and August 2017, respectively.

\subsection{Characteristics of the Vineyards and Irrigation Strategy}

Vine spacing in the 82 vineyards was at most $1.5 \mathrm{~m} \times 3 \mathrm{~m}$. Soils are quite homogenous in the Golan vineyards, consisting mainly of brown alluvial soils in the northern vineyards and peat soils in the southern vineyards. In Galilee and Judea vineyards, soils are much more heterogeneous, consisting mainly of basaltic and brown terra rossa soils.

The Mevo Beitar experimental vineyard, located within the Judea region $\left(31^{\circ} 43^{\prime} \mathrm{N} ; 35^{\circ} 06^{\prime} \mathrm{E}\right.$; red star in Figure 1a), covers a total area of 2.4 hectares. The average elevation of the vineyard area is 700 m.a.s.l. Grapevines (Vitis vinifera L. cv. Cabernet Sauvignon) were planted in 2011 in a northwest-to-southeast direction with a vine and row spacing of $1.5 \mathrm{~m}$ and $3.0 \mathrm{~m}$, respectively (Figure $1 \mathrm{~b}$ ). The height of the canopy typically varies between $2.0 \mathrm{~m}$ and $2.5 \mathrm{~m}$.

Irrigation in the 82 vineyards was through a surface drip irrigation system using unilateral cordons trained to vertical shoot positioning (VSP) on a 2-m-high two-wire trellis system. The irrigation control unit was set manually to be as close as possible to the agricultural standard practice [2,35]. The irrigation strategy used in the vineyards is of deficit irrigation based on $\mathrm{ET}_{\mathrm{o}}$ (reference evapotranspiration) information provided by the Israel Meteorological Service (IMS) from a nearest IMS station to the vineyard. In practice, irrigation was applied approximately once a week, with a daily amount that ranged between 0.8 and $1.43 \mathrm{~mm}$ per day in Mevo Beitar. Deficit irrigation started on DOY 131 (DI start; Figure 2) and was applied throughout the season until EOS. DI ranged along the season between $14 \%$ and $25 \%$ of the vine evapotranspiration (ETc) [2], while ETc was calculated from a modified leaf area index to crop coefficient ratio for vines [36,37].

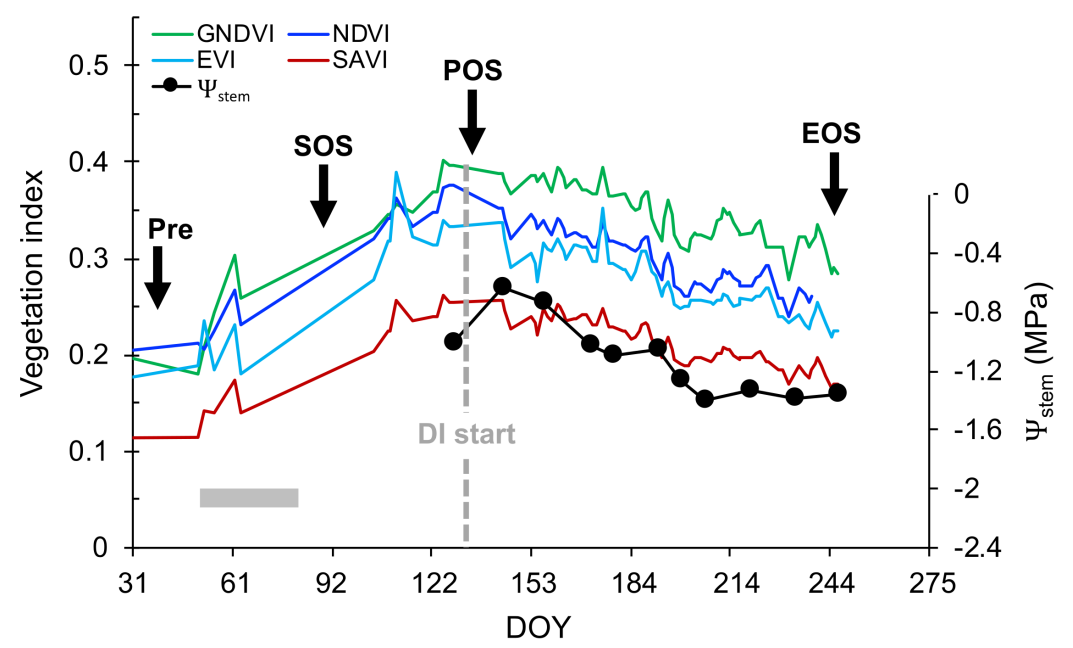

Figure 2. Daily time series of the four vegetation indices and weekly measured midday stem water potential $\left(\Psi_{\text {stem }}\right.$ ) along the grapevine growing season at Mevo Beitar (VIs are averaged values over all pixels within the vineyard area). Important phenological stages are shown (Pre-the pre-season period when vines are leafless and understory vegetation is absent or dry; SOS—start of season, coincident with budburst stage; POS—-peak of season, corresponding to full bloom stage; EOS—end of season, the harvest stage). DI start is the date when deficit irrigation started (DOY 131). Horizontal grey bar indicates the period of expansive presence of understory weeds and grasses in the vineyard. 
Other specific characteristics of the 81 commercial vineyards are summarized in Table A1.

\subsection{Measurements of Midday Stem Water Potential in Vineyards}

Measurements of $\Psi_{\text {stem }}$ were conducted periodically by a team of agronomists hired by the growers, approximately once a week in six grapevines per vineyard in each of the 81 commercial vineyards throughout the 2017 growing season. $\Psi_{\text {stem }}$ was measured prior to irrigation at solar noon (from 12:00 to 14:30), using a portable pressure chamber (model Arimad 2, Kfar Charuv, Israel and Arimad 3000, MRC, Hulon, Israel) according to the procedures described in [38]. Six sunlit, mature, fully expanded leaves from each vineyard were double bagged (plastic bags covered with aluminum foil) $1.5 \mathrm{~h}$ prior to measurement. The leaves were disconnected from the vines by sharp cutting of the leaf petiole and quickly placed in the pressure chamber. The time elapsing between leaf excision and chamber pressurization was less than $25 \mathrm{~s}$. The six grapevines were selected by visual observation as representative of the entire vineyard.

At the experimental vineyard in Mevo Beitar (Figure 1a, Figure A1), we measured $\Psi_{\text {stem }}$ in 60 plots (c. $5 \mathrm{~m}^{2}$ each) approximately every week during the 2017 growing season in order to monitor the spatial variability in $\Psi_{\text {stem }}$ across the vineyard area. Each plot contained two grapevines (total $\mathrm{N}=120$ vines), from which 4 leaves were taken for $\Psi_{\text {stem }}$ measurements. The $\Psi_{\text {stem }}$ measurements in Mevo Beitar were conducted using a portable pressure chamber (Arimad 3000, MRC, Hulon, Israel), as described above.

\subsection{Vegetation Indices}

We used four VIs in this study: the enhanced vegetation index (EVI), the soil-adjusted vegetation index (SAVI), and the abovementioned GNDVI and NDVI. These four VIs, as many others, are based on the ratio of solar reflection at the visible bands (RGB) to that at the near infrared (NIR) waveband (Table 1). The four VIs used here are regularly used in studies for tracking changes in plant-related traits, such as leaf growth (e.g., leaf area index), transpiration and evapotranspiration, as well as $\mathrm{CO}_{2}$ uptake and aboveground biomass from optical sensors mounted on unmanned aerial vehicles and/or satellites [9,17,39-42] (see also Box 1 in [32]).

Of the four VIs, NDVI is the most widely used [32]. Although NDVI has some saturation issues over dense vegetation [43], it was shown to be very reliable in monitoring vegetation dynamics, particularly in natural [8] and agricultural [16] Mediterranean vegetation systems. GNDVI, which is quite similar to NDVI, with the difference being that it uses the green instead of the red band (Table 1), is considered to be more sensitive to changes in chlorophyll-a concentrations compared to NDVI [44,45]. EVI and SAVI were both designed to overcome the saturation drawbacks in NDVI and GNDVI $[43,46]$. With a canopy background adjustment factor, both indices are considered to be efficient in terms of reducing soil background effects, with SAVI apparently being the most effective in that sense [43].

The four VIs were derived using the four spectral bands provided by Planet's images following the formulations given in Table 1.

Table 1. Formulation and source of the four vegetation indices used in this study.

\begin{tabular}{ccc}
\hline Index & Formulation ${ }^{1}$ & Reference \\
\hline GNDVI & GNDVI $=\frac{\rho\left(\lambda_{\text {NIR }}\right)-\rho\left(\lambda_{\text {Green }}\right)}{\rho\left(\lambda_{\text {NIR }}\right)+\rho\left(\lambda_{\text {Green }}\right)}$ & {$[45]$} \\
NDVI & NDVI $\left.=\frac{\rho\left(\lambda_{\text {NIR }}\right)-\rho\left(\lambda_{\text {Red }}\right)}{\rho\left(\lambda_{\text {NIR }}\right)+\rho\left(\lambda_{\text {Red }}\right)}\right)$ & {$[47]$} \\
EVI $^{2}$ & EVI $=\mathrm{G} \cdot \frac{\rho\left(\lambda_{\text {NIIR }}\right)+\rho\left(\lambda_{\text {Red }}\right)+C 1 \cdot \rho\left(\lambda_{\text {Red }}\right)-C 2 \cdot \rho\left(\lambda_{\text {Blue }}\right)+L_{1}}{\rho\left(\lambda_{\text {NIR }}\right.}$ & {$[43]$} \\
SAVI $^{3}$ & SAVI $=\left(1+L_{2}\right) \cdot \frac{\rho\left(\lambda_{\text {NIR }}\right)-\rho\left(\lambda_{\text {Red }}\right)}{\rho\left(\lambda_{\text {NIR }}\right)+\rho\left(\lambda_{\text {Red }}\right)+L_{2}}$ & {$[48]$} \\
\hline
\end{tabular}

${ }^{1} \rho$ is the surface reflectance and $\lambda_{\#}$ is the wavelength of a spectral band \#. ${ }^{2}$ The gain factor $G=2.5$; coefficients $\mathrm{C} 1=6.0$ and $\mathrm{C} 2=7.5$; and the canopy background adjustment factor $L_{1}=1.0$ are the standard values used for EVI.

${ }^{3}$ A standard canopy background adjustment factor $L_{2}=0.5$ for SAVI. 


\subsection{Phenological Stages}

We defined here three main phenological stages, which may be observed through changes in the VI time series (Figure 2). The three stages are: start of season (SOS), which corresponds to the time when the vines started their growth around DOY 80-90 (budburst stage), approximately one month prior to the start of the irrigation; peak of season (POS), when the canopy of the vines reached their full capacity (around DOY 120-140; full bloom stage); and end of season (EOS), around DOY 240-250, the harvest stage.

Expansive understory presence in the form of volunteer weeds and grasses occurs in Israeli vineyards around DOY 50-85 prior to SOS (see in Mevo Beitar vineyard; Figure 2). This understory vegetation was treated with herbicide in most of the Galilee vineyards and mechanically removed at the end of the spring in the Golan vineyards and in most of the vineyards in the Judea region.

Finally, pre-growth season (Pre) was defined here as the time when green vegetation (including understory weeds and grasses) is absent or dry in the vineyard, at approximately DOY 30 (Figure 2).

\subsection{Satellite Data}

\subsubsection{Planet Satellites}

Planet [34] is a commercial company running a constellation of small, standardized CubeSat 3U form factor $(10 \times 10 \times 30 \mathrm{~cm})$ nano-satellites of approximately $4 \mathrm{~kg}$ in mass. Planet currently operates more than 175 of the so-called 'Doves' PlanetScope (PS) nano-satellites, providing unprecedented daily nadir-pointing high-resolution land surface imaging of the entire earth. Planet's PS satellites provide images at a spatial resolution of $3 \mathrm{~m}$ (nadir ground sampling distance) in four spectral bands (RGB and NIR), with an equatorial overpass time of 9:30-11:30 a.m. (local time) [33], sometimes even three times a day (i.e., from different Doves). Planet Team currently provides a series of application programming interface (API) tools, such as Clips API [49].

In this study, a total of 3015 clipped PlanetScope Ortho Tiles were downloaded for 2017 using the Clips API for the vineyard areas within the three regions of interest (Figure 1a). Tiles were downloaded as TIFFs, often including several files for a specific date with also missing images in some dates due to cloudy conditions ( $<10 \%$ missing data). Figure A1 shows a true RGB color Planet image of Mevo Beitar vineyard alongside the plots where $\Psi_{\text {stem }}$ were measured (see Section 2.3), for comparison of scales.

\subsubsection{Building Time Series of Planet's Vegetation Indices in Google Earth Engine}

We used Google Earth Engine (GEE; https: / / earthengine.google.com/), which is a freely available cloud-based geospatial processing platform that combines a large catalog of satellite imagery and geospatial datasets with planetary-scale analysis capabilities [50]. All downloaded PS-clipped TIFFs, as well as the shapefile vector layers of the 82 vineyards (i.e., polygons), were uploaded as image- and feature collections to GEE. Then, GEE JavaScript API was used to: (1) calculate the four vegetation indices (VIs) for all images; (2) merge the number of images to a single image per date using a maximum value criteria (i.e., creating an image mosaic by selecting the maximum value for each pixel from all available images for that day) [43]. In this way, noisy data caused by cloud contamination and/or sensor view uncertainties were eliminated from the image; (3) generate time series of the four VIs; (4) calculate the time series of the averaged VI over the entire area of the vineyard (i.e., over all pixels within the vineyard area), for the 82 vineyards, and for the 60 plots within the vineyard area of Mevo Beitar (Figure 1b).

\subsubsection{Time Series Analysis}

To further eliminate noisy data in the time series, smoothing techniques are usually applied [32]. However, these techniques need the time series to be complete or at least have a predefined seasonal signal [51]. Because we aim at predicting $\Psi_{\text {stem }}$ from VIs without having prior information on the seasonal behavior of the vineyard, conventional smoothing techniques could not be used. Instead, 
we adopted a simple weekly average approach similar to a moving average on a complete time series to eliminate noisy data. We calculated the weekly average VI value (VI avg) for each vineyard. In addition, for the time series analysis the maximum and minimum VI values in each week were extracted (VI max and VI min, respectively). To further eliminate noise of background signal related to soil and/or understory vegetation, the VI avg was scaled by dividing it by the VI avg value at POS.

Another important variable used in the time series analysis is $\Delta \mathrm{VI}$, which is defined as the difference between the VI avg at POS and that at Pre, when green vegetation is absent in the vineyard. This $\Delta$ VI represents the difference in fractional vegetation cover between the two periods due to leaf expansion and canopy development of the vines. This means that vineyards with vines of less developed canopies will display a small $\Delta$ VI compared to those with more developed canopies. Because $\Psi_{\text {stem }}$ is from the vines and VI is a mixed signal from vines and background signal, we would expect a negative correlation between $\Delta \mathrm{VI}$ and the slope of the VI- $\Psi_{\text {stem }}$ relationship, meaning a weak VI response (steeper slope) to seasonal variations in $\Psi_{\text {stem, }}$, in vineyards with small $\Delta$ VI (less developed canopies).

\subsection{Statistical Analysis}

Three models were tested in this study:

1. A multivariable linear model with five variables (VI avg, VI max, VI min, $\Delta$ VI and day of year)

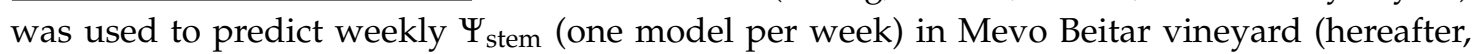
MB-Mult model).

2. A single linear regression model was used in Mevo Beitar to predict $\Psi_{\text {stem }}$ from VIs for the entire season using the VI time series (hereafter, MB-Reg model).

3. A single 'global' multivariable linear model with the same variables as in MB-Mult was used to predict seasonal $\Psi_{\text {stem }}$ from VI time series of the 81 commercial vineyards (hereafter, Global-Mult).

In Global-Mult, variables from all four VIs were first used in a single multivariable model with a total of 20 variables, five variables per VI. Then, to avoid multicollinearity issues in the model only the statistically significant variables $(p<0.05)$ with the highest size effect in the model were maintained, one VI per variable (total of five variables). The Global-Mult with the five variables was then used to predict $\Psi_{\text {stem }}$ in the experimental vineyard of Mevo Beitar, comparing it with MB-Mult and MB-Reg. It should be noted that in MB-Mult and Global-Mult, the values of the variables change along the season, while the value of $\Delta \mathrm{VI}$ remains the same.

Pearson's $r$ of the correlation, coefficient of determination $\left(R^{2}\right)$, and root square mean error (RMSE) were used as measures of model performance and to compare between the models. The size effect of each variable in Global-Mult, which is the effectiveness of the variable in predicting $\Psi_{\text {stem }}$, is presented as LogWorth, defined as $-\log 10$ ( $p$-value). The larger the LogWorth, the stronger is the effect of the variable in the model. All statistical analyses were carried out using JMP ${ }^{\circledR}$ software version 14.0 (SAS Institute Inc., Cary, NC, USA).

\section{Results}

\subsection{Deriving Midday Stem Water Potential for Mevo Beitar Vineyard}

Figure 2 shows daily time series of the four vegetation indices alongside the $\Psi_{\text {stem, }}$, while both VI and $\Psi_{\text {stem }}$ were averaged over the entire vineyard area at Mevo Beitar. In general, all four VIs showed a decreasing trend similar to that of the $\Psi_{\text {stem }}$ consequential to soil water depletion and increasing atmospheric demand for evapotranspiration. The inherent soil-background reduction capacity of SAVI is well noted in Figure 2, displaying the lowest values in comparison to the other three VIs (GNDVI, NDVI and EVI). 
Low VIs values in DOYs 30-50 (Pre stage) are related mainly to soil background and dry understory vegetation. Peak VI at POS is from the fully developed canopies of the vines at this time of the season, at the start of the irrigation.

MB-Reg was significant for all four VIs $(p<0.01)$, with $r=0.80-0.82$ (Figure 3). High VI values were generally associated with less negative $\Psi_{\text {stem }}$ at the time when DI started, while low VI values were associated with more negative $\Psi_{\text {stem, }}$, reflecting the water stress condition of the vines towards EOS (DOY 245).
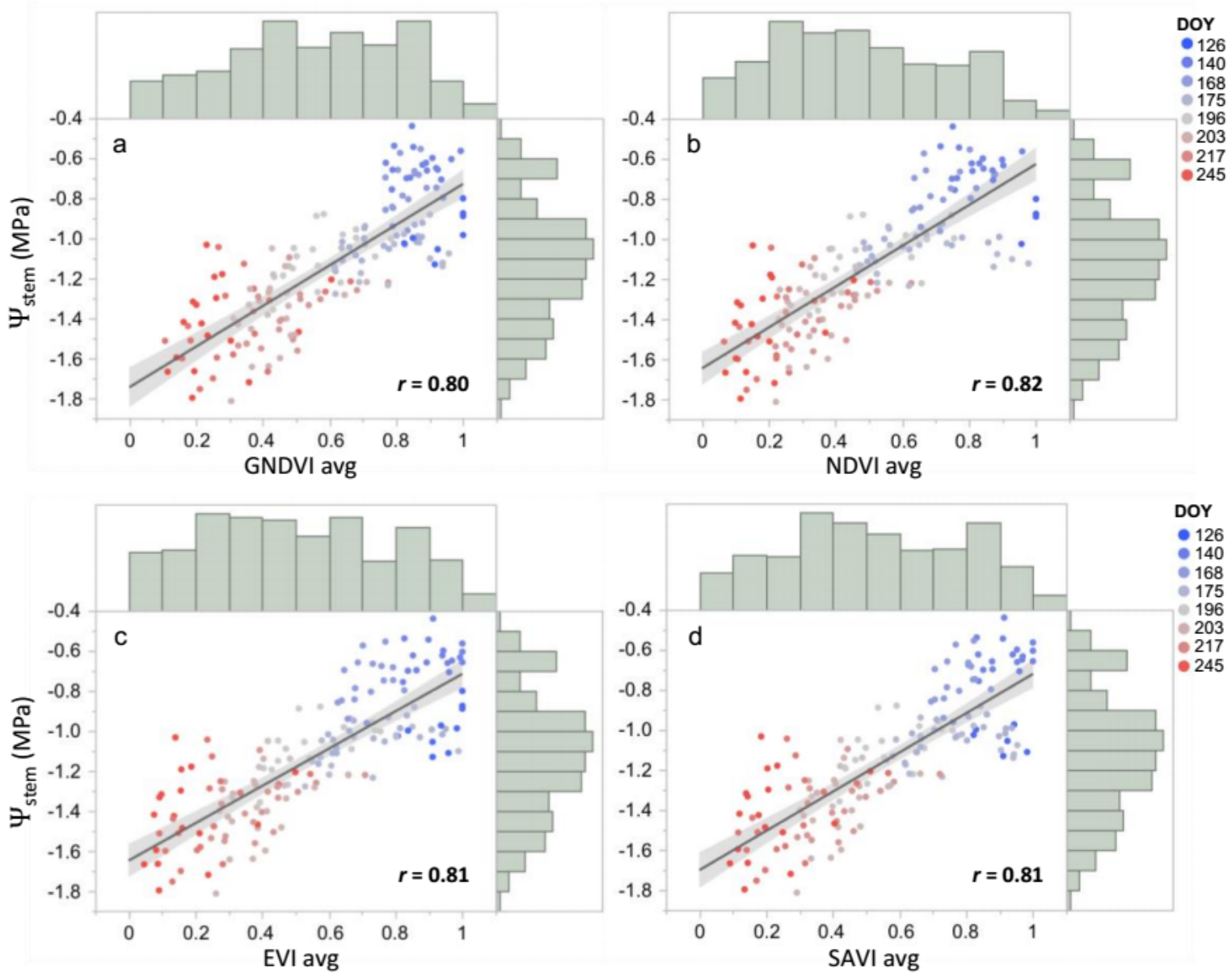

Figure 3. The correlation between the time series of VI avg and the measured $\Psi_{\text {stem }}$ in Mevo Beitar vineyard. Regressions presented are for the four VIs: (a) GNDVI, (b) NDVI, (c) EVI and (d) SAVI. Shaded band indicates $99 \%$ confidence intervals for the regression line.

Table 2 summarizes the statistics of MB-Mult for the four VIs. Here, again, SAVI showed a better performance than the other three indices, likely due to its higher capacity in reducing soil background effects. GNDVI, NDVI and EVI show quite similar $r$ scores, with NDVI showing a slightly better performance than GNDVI and EVI (Table 2). The highest $r$ scores were mostly obtained from DOY 189 towards EOS (DOY 245), although with a generally higher RMSE as well.

With the exception of one week (DOY 168), models were generally statistically significant along the season with an average $r$ score $>0.64$ (Table 2). It should be noted, though, that the week corresponding to DOY 168 was particularly cloudy, which likely affected Planet-derived VI and consequently the MB-Mult models in this particular week. 
Table 2. Statistics of the per-week multivariable linear models (MB-Mult) using the four Planet-derived VIs (GNDVI, NDVI, EVI and SAVI). The model with the highest Pearson's- $r$ and lowest RMSE (in MPa) scores is indicated in bold for each date. Low/high $r$ and RMSE scores along the season are denoted with blue/red colors per VI.

\begin{tabular}{|c|c|c|c|c|c|c|c|c|c|c|}
\hline \multirow{2}{*}{ DOY } & \multicolumn{4}{|c|}{$r$} & \multicolumn{4}{|c|}{ RMSE (MPa) } & \multicolumn{2}{|c|}{$\Psi_{\text {stem }}(\mathrm{MPa})$} \\
\hline & GNDVI & NDVI & EVI & SAVI & GNDVI & NDVI & EVI & SAVI & Average & Std \\
\hline 126 & 0.45 & $0.56^{2}$ & $0.56^{2}$ & $0.60^{3}$ & 0.091 & 0.084 & 0.084 & 0.081 & -1.008 & 0.126 \\
\hline 140 & $0.51^{1}$ & $0.48^{1}$ & 0.47 & $0.53^{1}$ & 0.049 & 0.050 & 0.050 & 0.048 & -0.633 & 0.103 \\
\hline 154 & $0.72^{3}$ & $0.76^{3}$ & $0.76^{3}$ & $0.78^{3}$ & 0.094 & 0.088 & 0.088 & 0.086 & -0.728 & 0.149 \\
\hline 168 & 0.32 & 0.32 & 0.30 & 0.28 & 0.129 & 0.129 & 0.129 & 0.130 & -0.990 & 0.226 \\
\hline 175 & 0.46 & $0.56^{1}$ & $0.56^{1}$ & $0.55^{1}$ & 0.065 & 0.061 & 0.061 & 0.061 & -1.089 & 0.130 \\
\hline 189 & $0.78^{3}$ & $0.76^{3}$ & $0.76^{3}$ & $0.78^{3}$ & 0.086 & 0.090 & 0.090 & 0.086 & -1.056 & 0.178 \\
\hline 196 & $0.76^{2}$ & $0.77^{2}$ & $0.77^{2}$ & $0.79^{3}$ & 0.087 & 0.085 & 0.085 & 0.082 & -1.250 & 0.145 \\
\hline 203 & $0.76^{3}$ & $0.74^{3}$ & $0.73^{3}$ & $0.75^{3}$ & 0.124 & 0.128 & 0.128 & 0.125 & -1.408 & 0.198 \\
\hline 217 & $0.84^{3}$ & $0.81^{3}$ & $0.81^{3}$ & $0.82^{3}$ & 0.108 & 0.116 & 0.116 & 0.115 & -1.196 & 0.447 \\
\hline 245 & $0.84^{3}$ & $0.79^{3}$ & $0.79^{3}$ & $0.81^{3}$ & 0.147 & 0.166 & 0.166 & 0.160 & -1.364 & 0.285 \\
\hline Average & 0.64 & 0.65 & 0.65 & 0.67 & 0.098 & 0.099 & 0.100 & 0.097 & -1.072 & 0.199 \\
\hline
\end{tabular}

Figure 4 shows high-resolution maps of $\Psi_{\text {stem }}$ in Mevo Beitar vineyard from MB-Mult using SAVI for selected dates. The spatial pattern of $\Psi_{\text {stem varies throughout the growing season (Figure } 4) . \Psi_{\text {stem }}}$ in DOY 154 was relatively high across the vineyard compared to other dates because of the DI start in DOY 131 (Figure 2) and the relatively lower atmospheric demand compared to the following weeks.

Figure 5 shows the difference $(\Delta \Psi)$ between the $\Psi_{\text {stem }}$ derived from MB-Reg and MB-Mult (both using SAVI). $\Delta \Psi$ in Figure 5 was calculated as the absolute $\Psi_{\text {stem }}$ value from MB-Reg minus the absolute $\Psi_{\text {stem }}$ value from MB-Mult. Thus, blue colors indicate lower values of $\Psi_{\text {stem }}$ (more stressed) in MB-Reg than in MB-Mult, while red colors mean that $\Psi_{\text {stem }}$ was higher (less stressed) in MB-Reg than in MB-Mult. Most of the maps in Figure 5 show a uniform distribution of $\Delta \Psi$ across the vineyard, which means that MB-Reg was able to reproduce the spatial variability in $\Psi_{\text {stem }}$ close to that predicted by MB-Mult, though with some differences in magnitude. Yet, at both ends of the growing season, before and after the DI start (DOY 126 and 245), $\Delta \Psi$ across the vineyard shows a significant spatial variability.

These results indicate that the measures from both models are consistent with one another for much of the season. Thus, for irrigation management, either approach could be used to monitor relative difference (spatial variability) within the field at Mevo Beitar, to the extent that such information could be used to improve the efficiency of ground operations. 
DOY 126

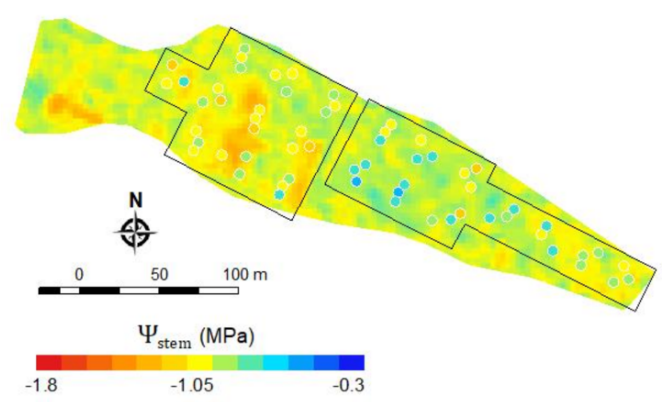

DOY 189

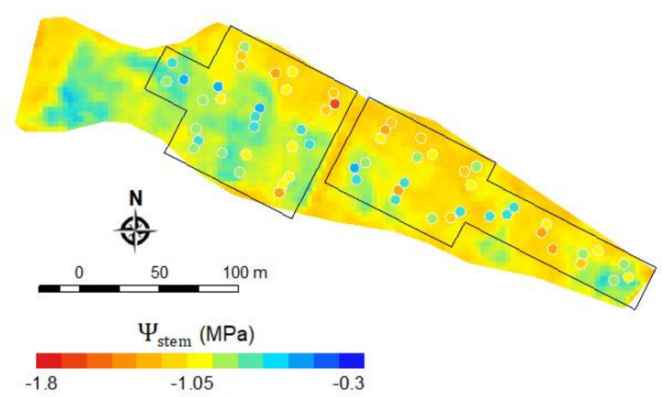

DOY 217

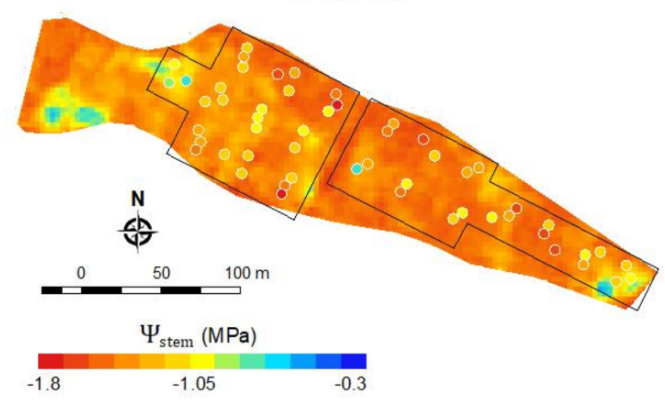

DOY 154

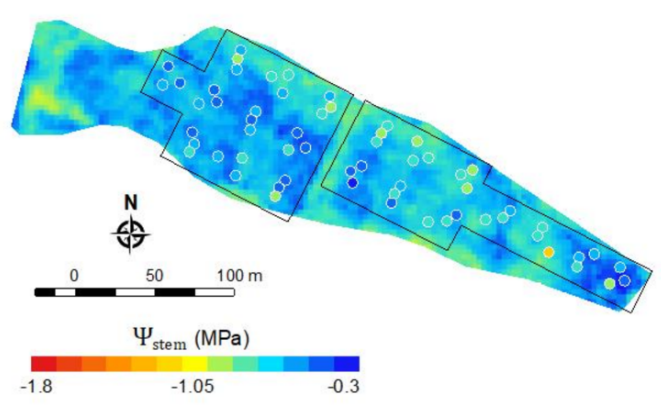

DOY 203

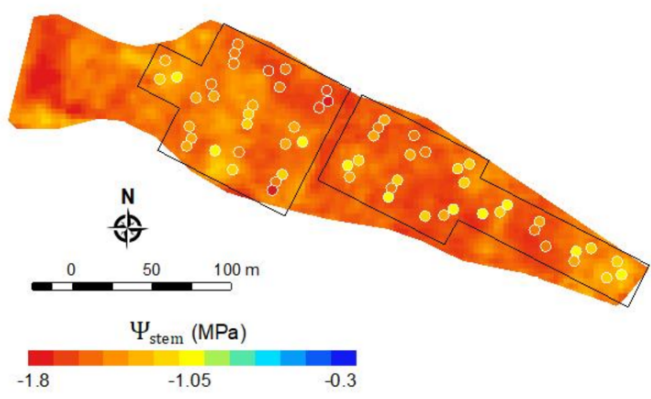

DOY 245

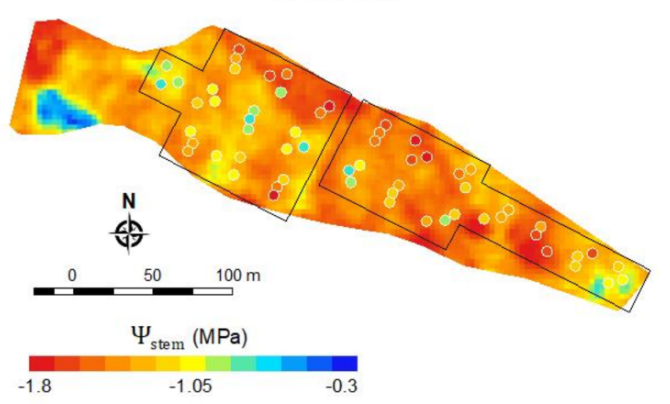

Figure 4. High-resolution $\Psi_{\text {stem }}$ maps of Mevo Beitar vineyard derived from MB-Mult (the multivariable regression model) using SAVI for selected weeks along the season. Plots $\Psi_{\text {stem }}$ measured values are also shown in circles. Note that all figures in this panel use the same legend and scale. 
DOY 126

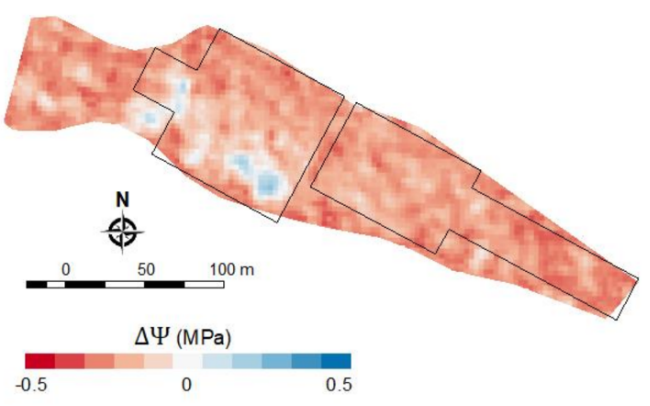

DOY 189

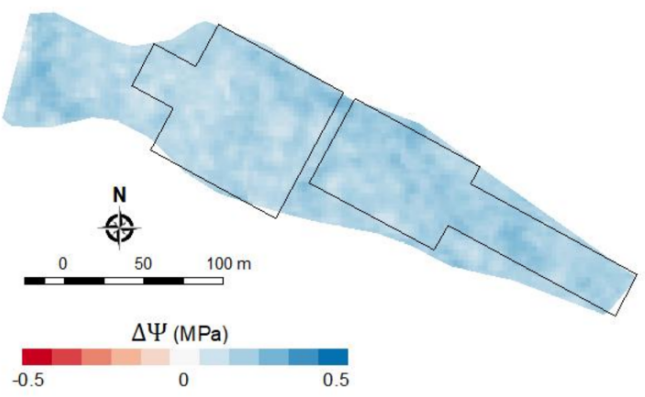

DOY 217

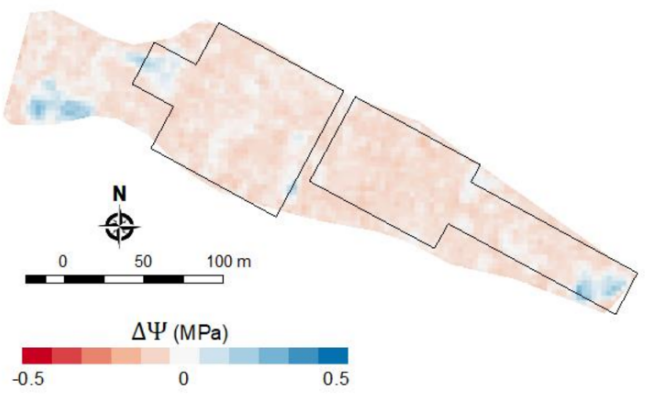

DOY 154

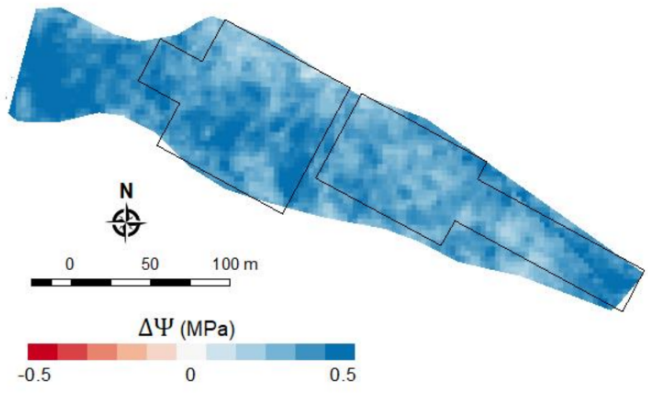

DOY 203

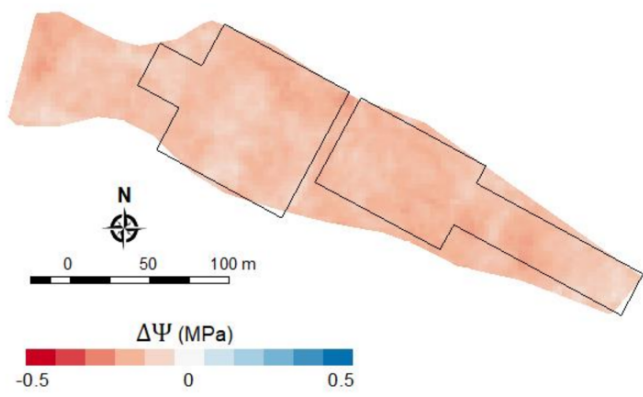

DOY 245

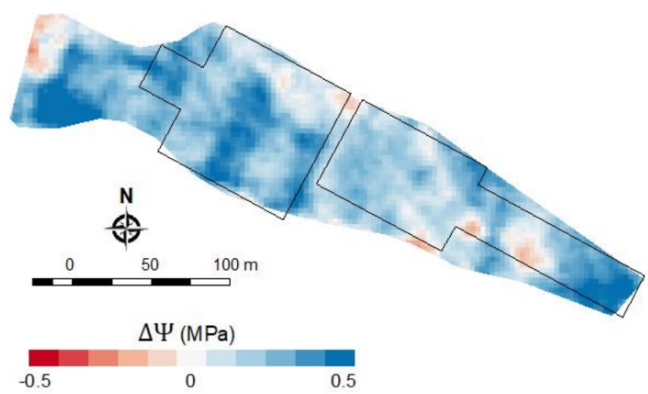

Figure 5. The difference between the $\Psi_{\text {stem }}$ maps retrieved from MB-Mult and MB-Reg, both using

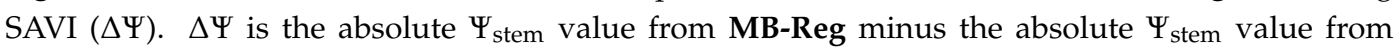
MB-Mult; therefore, blue color indicates a lower $\Psi_{\text {stem }}$ value (more stressed) in MB-Reg compared to MB-Mult, while red color indicates a higher $\Psi_{\text {stem }}$ value (less stressed) in MB-Reg compared to MB-Mult.

\subsection{Vegetation Indices and Stem Water Potential in Vineyards across Rainfall Gradient}

The Pearson's $r$ of the VI- $\Psi_{\text {stem }}$ linear fit using all data from the 82 vineyards together was positive and significant $(p<0.001)$, with $0.58<r<0.68$ for the four VIs (Figure 6). Once again, SAVI was demonstrated to be the most successful index in tracking seasonal changes in $\Psi_{\text {stem }}$ in the 82 vineyards (Figure 6d).

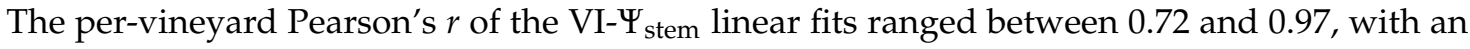
average $r$ of $0.85 \pm 0.06$ (Figure 7 ). Linear fits, though, differed between vineyards in terms of intercept and particularly in slope (Figures 6 and 7). 

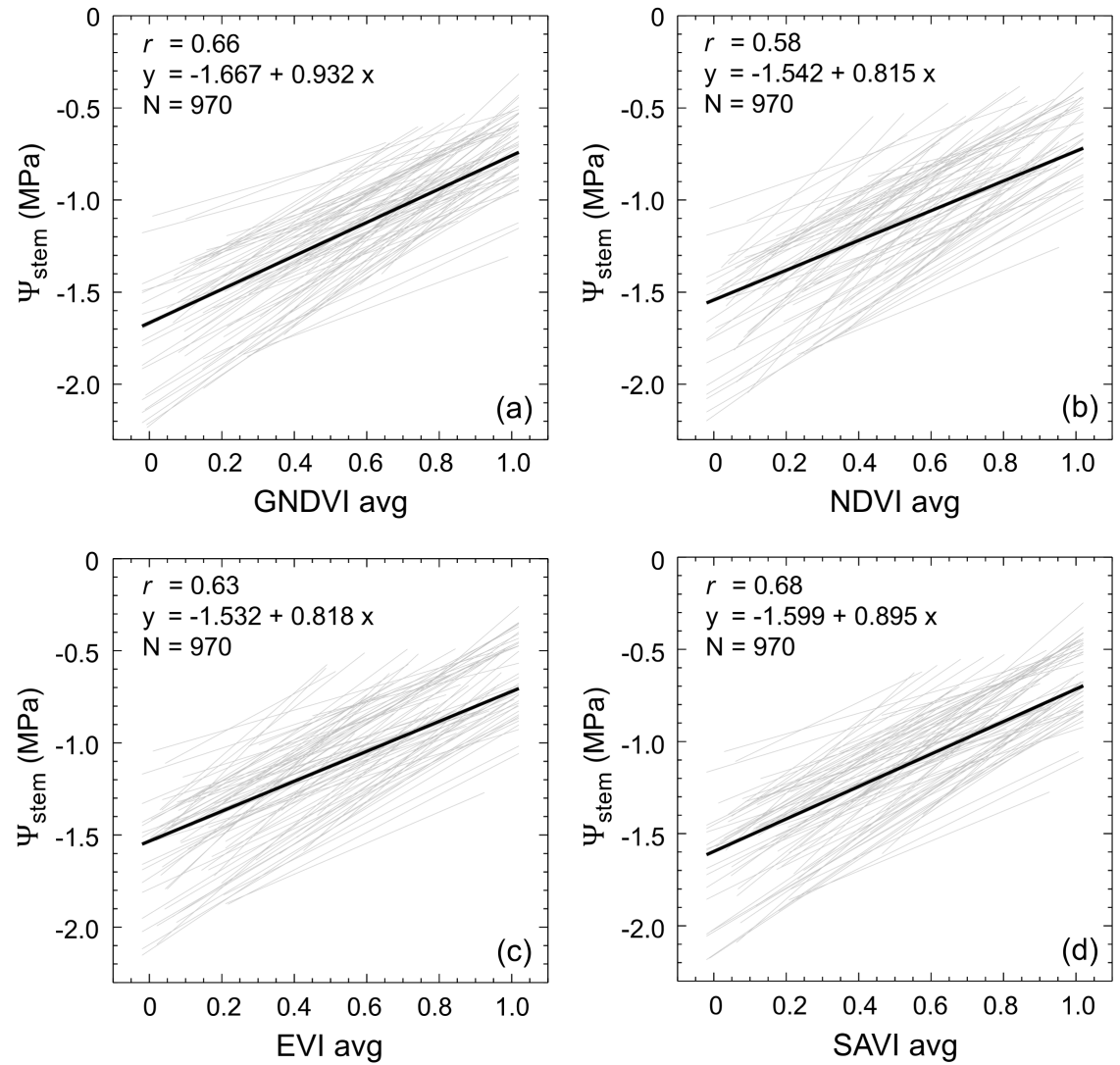

Figure 6. Linear relationships between Planet-derived VI avg: (a) GNDVI, (b) NDVI, (c) EVI and (d) SAVI, and $\Psi_{\text {stem }}$ in 82 vineyards (grey lines). The general linear fit using all data is also shown (black bold line).

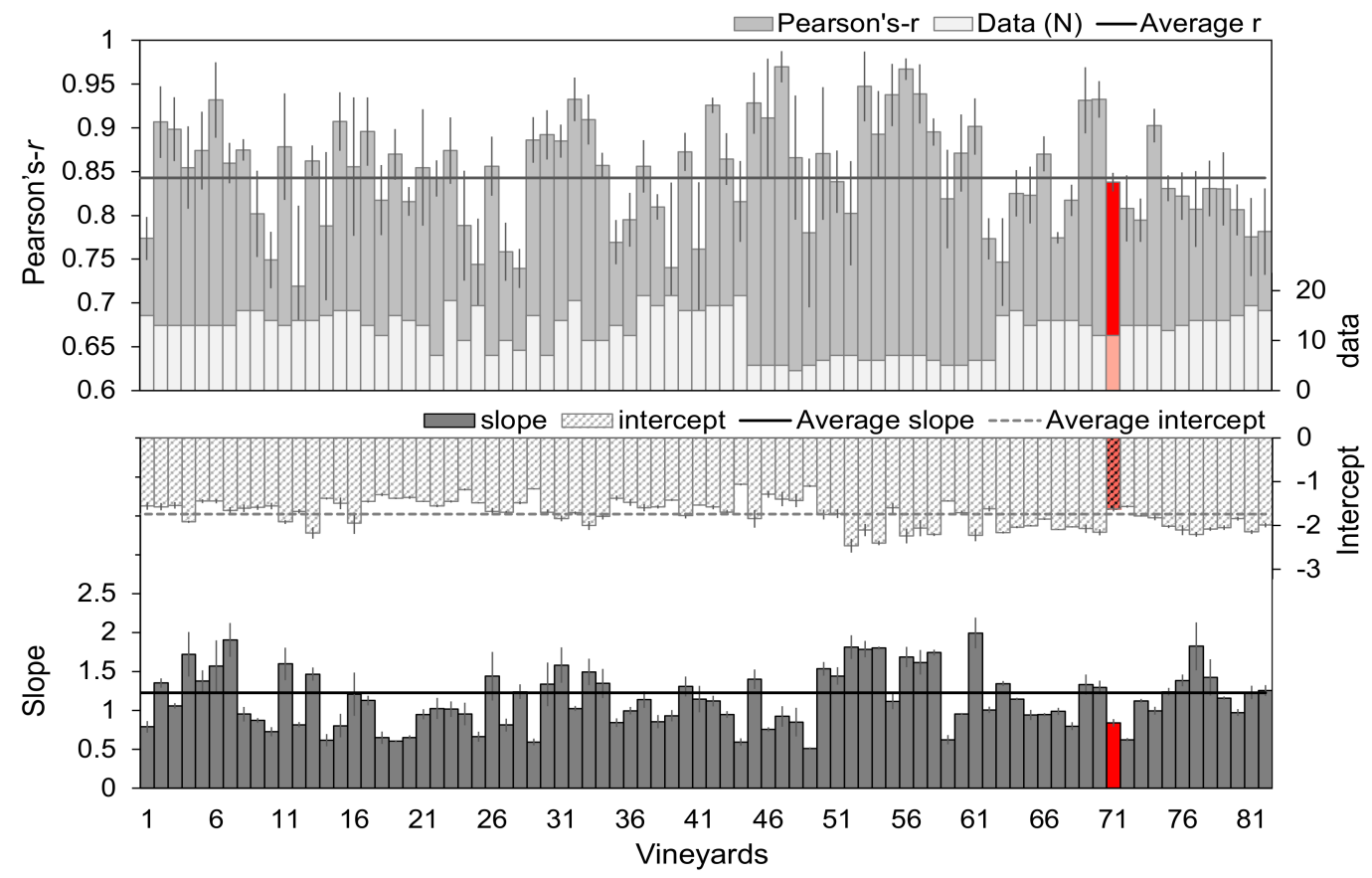

Figure 7. Pearson's-r, number of data-dates available along the season $(\mathrm{N})$, slope and intercept of the linear fit of VI avg vs. $\Psi_{\text {stem }}$ in single vineyards (see 82 vineyards in Table A1). The $r, \mathrm{~N}$, slope and intercept were averaged over the four VIs. Error bars denote $\pm 1 \sigma$. Mevo Beitar vineyard is indicated in red. 
Background effects of soil and/or understory vegetation were likely responsible for the different slopes of the linear fits (Figures 6 and 7). Vineyards with a large background effect had more pronounced slopes, meaning weak VI response to seasonal changes in $\Psi_{\text {stem }}$. This background effect may be noted as a negative correlation between $\Delta \mathrm{VI}$ and the slope of the VIs- $\Psi_{\text {stem }}$ linear fit in Figure 8.
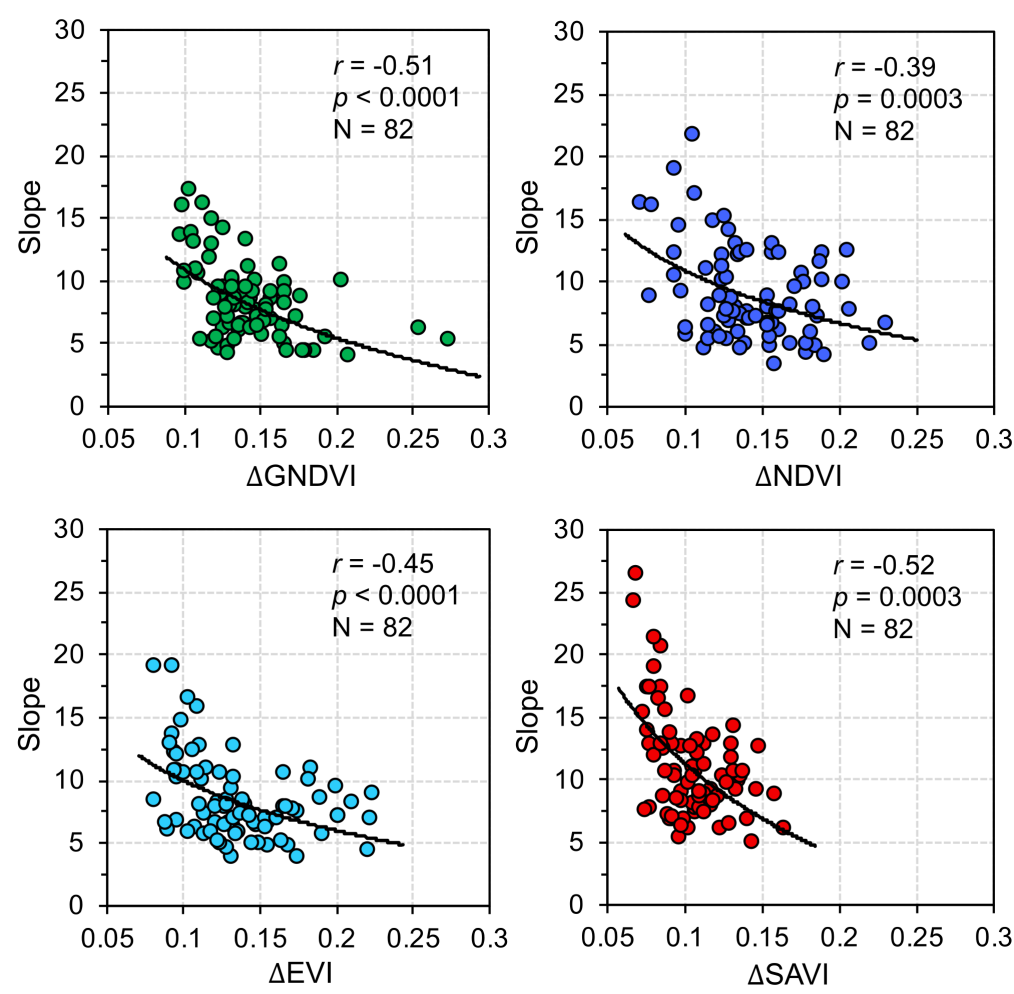

Figure 8. The relationship between the $\Delta \mathrm{VI}$ and the slope of the VI- $\Psi_{\text {stem }}$ linear fit in the 82 vineyards. Notice that a larger slope signifies weaker response of VI to increasing stress (i.e., to decreasing $\Psi_{\text {stem }}$ ).

Figure 8 shows that for vineyards with a small $\Delta$ VI (weak VI response to $\Psi_{\text {stem }}$ change), or, in other words, with grapevines of less developed canopies and thus a larger background effect, the slope of the VIs- $\Psi_{\text {stem }}$ linear fit was steeper than for vineyards with a large $\Delta$ VI. This suggests that $\Delta$ VI is an important variable in predicting $\Psi_{\text {stem }}$ and may assist in distinguishing between vineyards with different levels of background effect.

The performance of each of the four VIs in a multivariable regression model (one model per VI) was quite similar ( $r=0.76$, for the four VIs), with a slight improvement $(r=0.78$; RMSE $=18.5 \%$; Figure 9) when using variables from different VIs in Global-Mult (Table 3). Global-Mult, though, was a significant improvement over the simple linear regression model used with the VI time series $(0.58<r<0.68$, Figure 6$)$. 


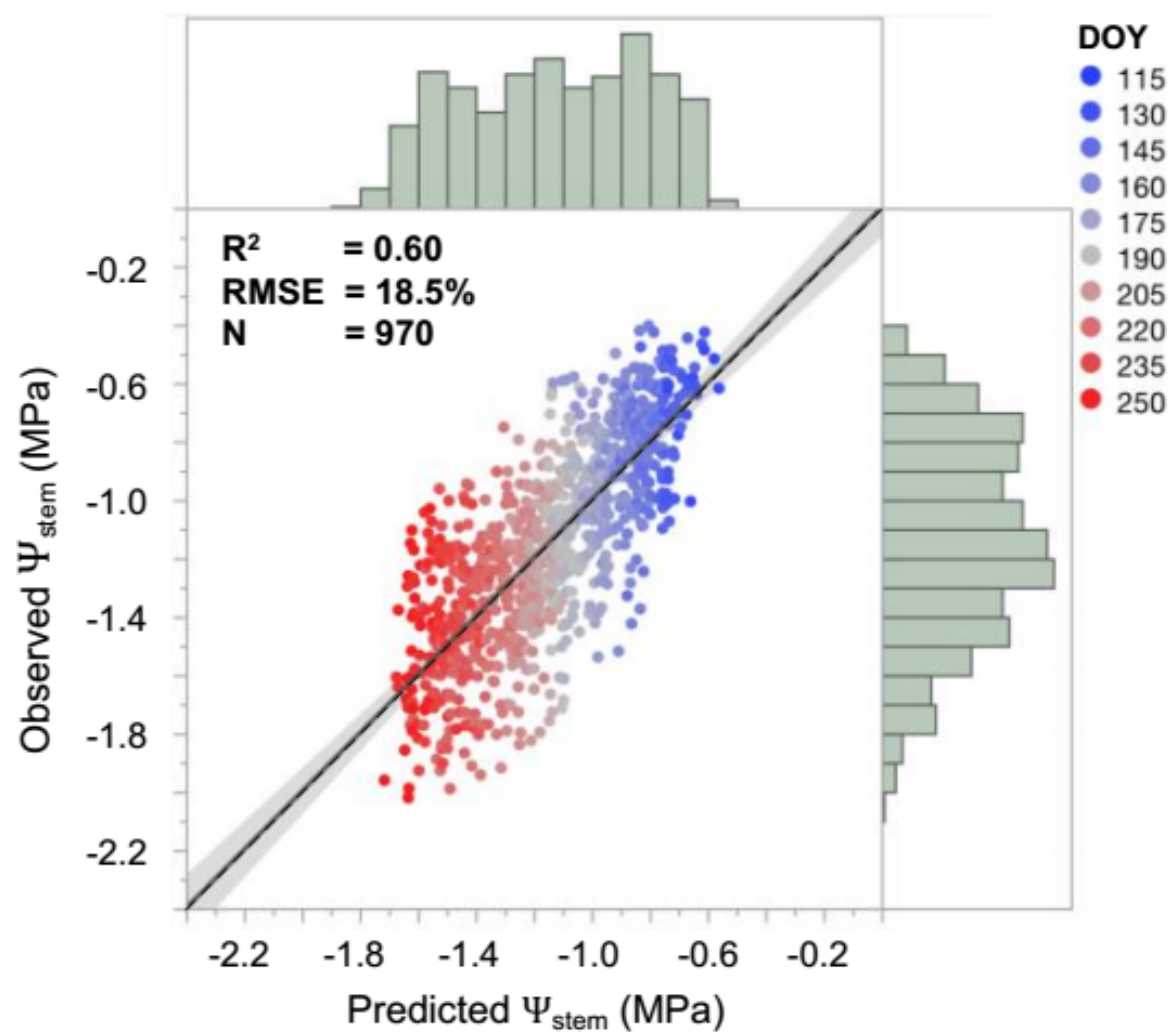

Figure 9. Results of predicted (using the 'global' multivariable regression model) vs. observed $\Psi_{\text {stem }}$ in the 82 vineyards along the 2017 growing (dashed line indicates 1:1 slope).

Table 3. Size effects (LogWorth) and estimates of the variables used in the 'global' multivariable regression model (i.e., the coefficients of the variables used in the linear model). The table was arranged from the variable with the highest to the lowest effect in the model.

\begin{tabular}{cccccc}
\hline Variable & Estimate $^{\mathbf{1}}$ & $\boldsymbol{\sigma}^{\mathbf{2}}$ & t-Ratio $^{\mathbf{3}}$ & LogWorth & $\boldsymbol{p}_{\text {-Value }} \mathbf{4}^{\mathbf{2}}$ \\
\hline DOY & -0.0062 & 0.00045 & -13.59 & 37.906 & $<0.0001$ \\
DNDVI & 2.5164 & 0.37276 & 6.75 & 10.596 & $<0.0001$ \\
SAVI avg & 0.6570 & 0.09927 & 6.62 & 10.219 & $<0.0001$ \\
NDVI max & -2.4509 & 0.43914 & -5.58 & 7.508 & $<0.0001$ \\
NDVI min & -1.0344 & 0.37159 & -2.78 & 2.261 & 0.0055 \\
Intercept & -0.3885 & 0.13803 & -2.81 & & 0.0050 \\
\hline
\end{tabular}

${ }^{1}$ The estimated coefficient value of the variable in the model. ${ }^{2}$ The standard deviation on estimated coefficient value. ${ }^{3}$ The $t$-Ratio of the estimated variable in the model. ${ }^{4}$ The significance of the variable in the model.

As for the size effect (LogWorth) of each variable in the model, DOY was the one with the strongest effect (Table 3). The variable with the next-strongest effect was $\triangle$ NDVI, meaning a strong background effect in the vineyards, as already suggested by the relationship shown in Figure 8. The SAVI avg had also a significant effect, comparable to the size effect of $\Delta$ NDVI (Table 3).

\subsection{Predicting Stem Water Potential at Mevo Beitar Vineyard Using Single 'Global' Model}

Figure 10 shows the comparison between measured $\Psi_{\text {stem }}$ averaged over the 60 plots at Mevo Beitar vineyard during the season of 2017 and predicted $\Psi_{\text {stem }}$ using MB-Reg, MB-Mult and Global-Mult. 

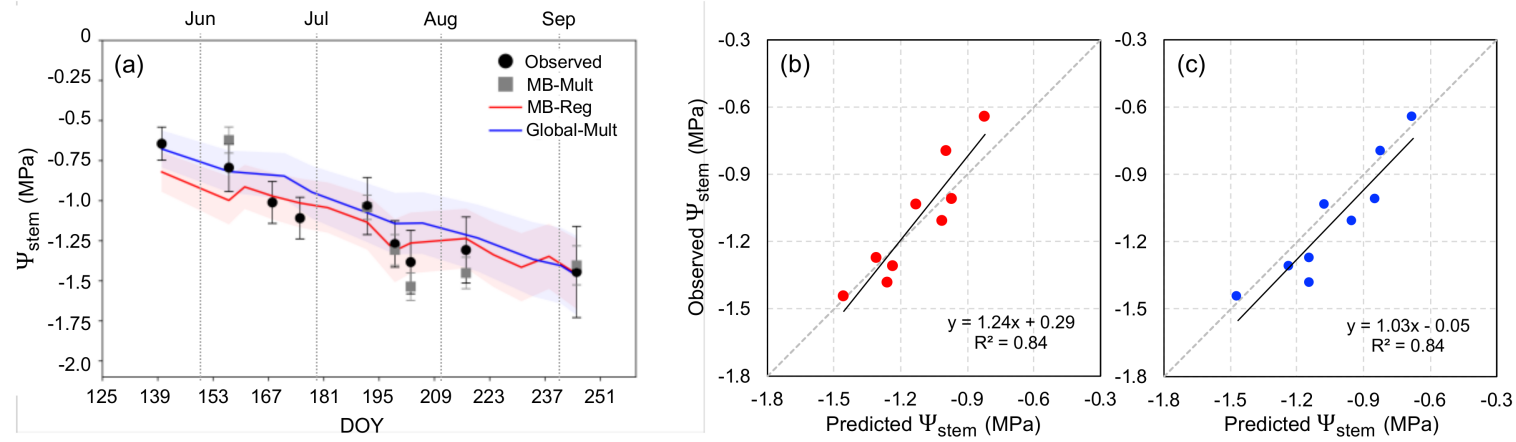

Figure 10. (a) Observed and predicted $\Psi_{\text {stem }}$ at Mevo Beitar vineyard for the 2017 growing season. Predicted $\Psi_{\text {stem }}$ was derived using the site-specific per-week multivariable MB-Mult model, the site-specific MB-Reg model, and the Global-Mult model. Red and blue shaded bands in (a) indicate model uncertainties in MB-Reg and Global-Mult, respectively, while error bars in MB-Mult and observations denote $\pm 1 \sigma$. Scatterplot of observed vs. predicted $\Psi_{\text {stem }}$ for (b) MB-Reg and (c) Global-Mult.

Global-Mult is shown to reproduce seasonal changes in observed $\Psi_{\text {stem }}$ at Mevo Beitar with a fairly high accuracy $\left(R^{2}=0.84\right.$; RMSE $=0.12$; bias $=0.07$, Figure $\left.10 \mathrm{a}, \mathrm{c}\right)$, at least as good as the site-specific models of MB-Reg $\left(R^{2}=0.84\right.$; RMSE $=0.11$; bias $=-0.02$, Figure 10a,b) and MB-Mult (Figure 10a). Thus, Global-Mult appears to present a useful tool for seasonal (weekly) predictions of $\Psi_{\text {stem }}$ in Mediterranean vineyards.

\section{Discussion}

Management of spatial variability within a vineyard can increase profits significantly by allowing optimization of yield quantity and quality [52,53]. Technologies and methodologies are currently being developed to allow variable-rate irrigation in drip irrigated vineyards and orchards [54,55]. Since the current state of the art for irrigation decision-making uses time- and labor-consuming measurement of $\Psi_{\text {stem }}[2,35,36,56]$, remote sensing methodologies successfully acting as stem water potential proxies have particular appeal. That said, there remains a challenge in finding remotely acquired data that: (a) has sufficiently reliable correlation with $\Psi_{\text {stem, }}$ (b) is affordable and accessible, and (c) has both high spatial and temporal resolution, each of which are necessary in order for the method to be useful for high frequency irrigation scheduling.

This study showed a significant correlation between vegetation indices derived from high-resolution Planet images (3-m) and $\Psi_{\text {stem }}$ in Mediterranean (Israel) vineyards. Previous studies have shown that CWSI and NIR-based indices, like GNDVI and NDVI, may be good indicators of water status in grapevines through correlations with leaf stomatal conductance $\left(g_{s}\right)$ and water potential ( $\Psi_{\text {Leaf }}$ and $\left.\Psi_{\text {stem }}\right)$. However, these relationships were mostly observed at the canopy- $[22,28,29]$ or leaf $[30,31]$ levels using manual spectroradiometers or sensors mounted on small airplanes and drones. As far as the authors are aware, this is the first study that shows such a relationship using images of coarser spatial resolution acquired from satellites, and more specifically from Planet nano-satellites.

One of the main challenges when using satellite information is the spatial resolution of the images, which is often coarser than the targeted object and may induce a mixed-pixel signal effect. For example, understory vegetation was shown to affect satellite spectral signals in complex vegetation systems comprised of multi-canopy layers [32]. The multi-canopy layer, vertical mixed-pixel effect was further corroborated in a simulation model by Chen et al. [57], implying that understory vegetation may significantly affect satellite signals. In our case, understory expansion reaches its maximum at $\sim$ DOY 60, while vines budburst occurs later at DOY 80-90. Background effect in the vineyards, which may include the signal from soil and/or understory vegetation, was observed through a different $\mathrm{VI}-\Psi_{\text {stem }}$ linear fit in terms of magnitude of slope (slope ranged between 0.5 and 2), meaning that some 
vineyards experienced weak VI response to seasonal changes in $\Psi_{\text {stem, }}$ while others experienced a stronger response to $\Psi_{\text {stem }}$ changes. This differential response is due to the fact that in vineyards with grapevines of more developed canopies, and consequently less exposed understory cover seen from the satellite, the VI signal is mostly coming from the vines while in vineyards with less developed vines much of the VI signal comes from the ground.

To overcome this mixed-pixel effect, we used the difference between the VI signal at the POS, which corresponded mainly to the grapevines, and that of the understory derived at the Pre $(\Delta \mathrm{VI})$. That way, background effects were eliminated allowing vineyards with diverse soil and understory vegetation characteristics to be compared and used in a single 'global' model. Results from the Global-Mult model showed that $\Delta$ NDVI had a significant size effect, being a key factor in predicting $\Psi_{\text {stem }}$, with only day of year having a stronger size effect and SAVI avg a similar effect (Table 3).

In Mevo Beitar, a highly variable vineyard, weekly based correlations (Pearson's $r$ ) of GNDVI, NDVI, EVI and SAVI vs. $\Psi_{\text {stem }}$ were within the range of $0.28-0.84$, with an average value of 0.65 for all indices (Table 2). These results were quite similar to previously reported VI- $\Psi_{\text {stem }}$ correlations found by others using very-high-resolution images [22,29]. When time series were used in the regression instead of date-specific data, correlations were even higher $(0.80<r<0.82)$. A simple linear regression model (MB-Reg) was sufficient to reproduce temporal, as well as spatial variations in $\Psi_{\text {stem }}$ in the experimental vineyard.

In general, correlations from simple specific-date regressions between vegetation indices and $\Psi_{\text {stem }}$ were also high for the 81 commercial vineyards ( $r=0.72-0.97$; Figure 7$)$, implying that Planet-derived time series of vegetation indices like, GNDVI, NDVI, EVI and SAVI may be good indicators of water status at the vineyard-scale level.

Finally, the Global-Mult model with spectral-based indices derived from Planet satellites was proposed to predict $\Psi_{\text {stem }}$ in Mediterranean vineyards. After deriving $\triangle$ NDVI, SAVI avg, NDVI max and NDVI min of a specific vineyard a real-time $\Psi_{\text {stem }}$ estimation may be provided for that vineyard at a weekly basis. The Global-Mult shows promise in improving the efficiency of in-field conventional monitoring efforts.

\section{Conclusions}

The relationship between stem water potential and vegetation indices was evaluated in Mediterranean vineyards through the use of high spatial resolution Planet nano-satellite imaging on the freely available GEE cloud computing system for the first time. Using JavaScript API in GEE allowed fast computation of the derivation of time series of vegetation indices for the area of the 82 vineyards, showing potentials for real-time monitoring in small-size agricultural fields.

The four vegetation indices tested in this study (GNDVI, NDVI, EVI and SAVI) showed significant correlation with stem water potential, with SAVI displaying a slightly better performance, likely due to its capacity for reducing soil effects. Correlations using of the four vegetation indices were high for measurements across the vineyard area $(0.89<r<0.82$ for MB-Reg and $0.64<r<0.67$ for MB-Mult) and along the season ( $r=0.92$ for both MB-Reg and Global-Mult), allowing predictions of stem water potential variability in space and time.

A method to reduce the background effect of understory vegetation and soil, which accounts for the fractional cover of the vines, was also presented. The fractional cover of the vines was retrieved as the difference in the value of the vegetation index at the peak of season and prior to the appearance of green vegetation in the vineyard $(\Delta \mathrm{VI})$. This $\Delta \mathrm{VI}$, was negatively correlated with the slope of the vegetation index to stem water potential relationship, meaning that vineyards with a low fractional cover have weak VI response to changes in measured stem water potential. Using the $\Delta$ VI allowed the development of a 'global' multivariable model for predicting stem water potential in vineyards with different background (soil and understory presence) characteristics.

Overall, the approach presented here shows promise in exploiting these technologies, which include resolving the mixed-pixel problem in agricultural as well as in the ecological monitoring of 
natural vegetation systems from satellites. The tools developed here, i.e., the combination of Planet images and GEE platform, with the aforementioned mixed-pixel separation approach, may be also used for water status monitoring of agricultural fields other than vineyards.

Finally, pending further verification and validation, the proposed 'global' model presented here may be used for real-time irrigation management along the season from the abovementioned weekly values extracted using daily Planet images. Using the 'global' model could substantially improve sampling efficiency of conventional water status monitoring. The methodology developed in this study should be further examined with supporting information on soil texture, LAI/fractional cover and understory vegetation. Moreover, a comparison with freely available satellite images like those from Sentinel-2, which have coarser spatial (10-20 m) and temporal (5 day) resolution than Planet, should be conducted.

Author Contributions: Conceptualization, D.H. and Y.C.; Data curation, A.P.; Formal analysis, D.H.; Funding acquisition, A.B.-G., V.A. and Y.C.; Investigation, D.H., I.B., Y.N., A.B.-G., A.P. and Y.C.; Methodology, D.H.; Project administration, V.A. and Y.C.; Resources, I.B., A.B.-G., V.A. and Y.C.; Software, D.H.; Supervision, Y.C.; Validation, D.H., I.B. and Y.N.; Visualization, D.H.; Writing-original draft, D.H.; Review \& editing, D.H., Y.C., Y.N., I.B., A.B.-G., A.P. and V.A.

Funding: This research was funded by the Chief Scientist Fund of the Ministry of Agriculture and Rural Development in Israel, grant number [20-12-0030].

Acknowledgments: The authors thank Itamar Lensky for fruitful discussions, Yaron Michael and Shilo Shif for assisting with GEE Java script and Planet's Clip API, and Planet Labs for providing API tools and images, as part of Planet's Education and Research Program. We also thank Ben Hazut, for assistance in the field and laboratory, Yair Hayat from Barken Winery, Shlomo Zsadok and Tamar Sokolsky from Golan Heights Winery, David Twito and Dror Dotan from Carmel wineries for agro-technical assistance. This research was supported by the Chief Scientist Fund of the Ministry of Agriculture and Rural Development in Israel (Grant No. 20-12-0030).

Conflicts of Interest: The authors declare no conflict of interest. The funders had no role in the design of the study; in the collection, analyses, or interpretation of data; in the writing of the manuscript, and in the decision to publish the results.

\section{Appendix A}

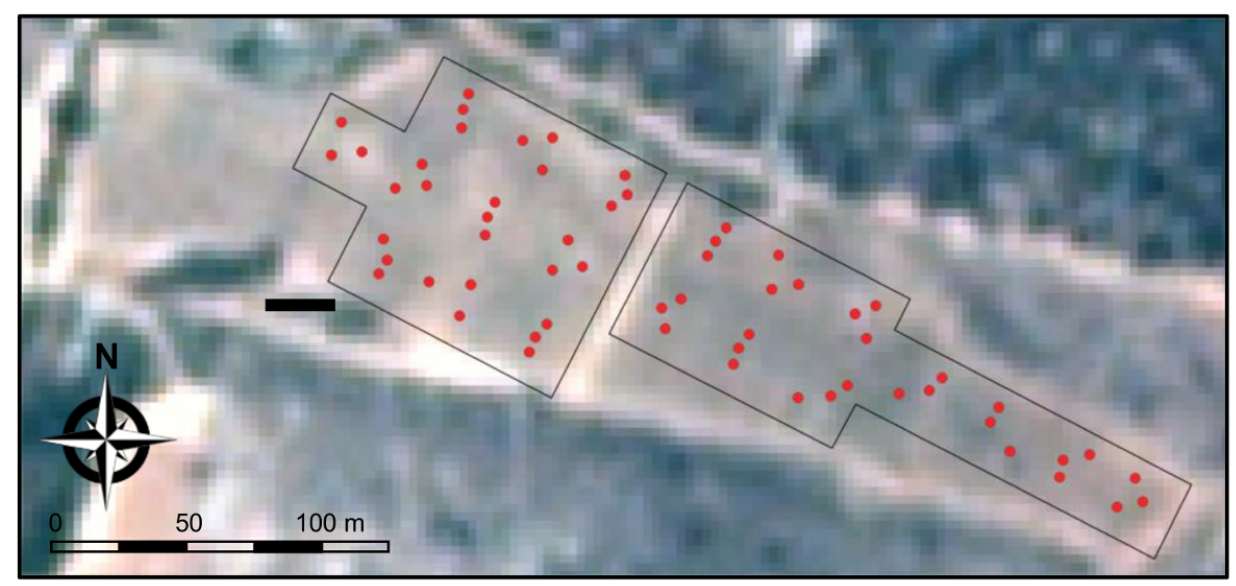

Figure A1. A true RGB color Planet image (from 3 June 2016) of Mevo Beitar vineyard with location of the $60 \Psi_{\text {stem }}$ measurement plots. 
Table A1. General characteristics of the 82 vineyards used in this study. The region, size of the vineyard (in hectares) and species are shown alongside the minimum (most negative) seasonal $\Psi_{\text {stem }}(\mathrm{MPa})$ in the vineyard and the DI start and EOS dates. In bold is Mevo Beitar vineyard.

\begin{tabular}{|c|c|c|c|c|c|c|c|}
\hline$\#$ & Region & Size (ha) & Species & Red/White & $\Psi_{\text {stem }}(\mathrm{MPa})$ & DI Start & EOS \\
\hline 1 & Golan & 1.74 & Cabernet Franc & red & -1.376 & 14-May & 27-Aug \\
\hline 2 & Golan & 1.34 & Chardonnay & white & -1.721 & 28-May & 10-Sep \\
\hline 3 & Golan & 0.95 & Chardonnay & white & -1.518 & 28-May & 10-Sep \\
\hline 4 & Golan & 1.30 & Cabernet Sauvignon & red & -1.806 & 28-May & 10-Sep \\
\hline 5 & Golan & 0.85 & Cabernet Sauvignon & red & -1.500 & 28-May & 10-Sep \\
\hline 6 & Golan & 0.70 & Cabernet Sauvignon & red & -1.427 & 28-May & 10-Sep \\
\hline 7 & Golan & 1.16 & Cabernet Sauvignon & red & -1.743 & 28-May & 10-Sep \\
\hline 8 & Golan & 1.00 & Cabernet Sauvignon & red & -1.543 & 14-May & 05-Sep \\
\hline 9 & Golan & 1.42 & Cabernet Sauvignon & red & -1.533 & 14-May & 05-Sep \\
\hline 10 & Golan & 2.07 & Merlot & red & -1.432 & 14-May & 14-Aug \\
\hline 11 & Golan & 1.30 & Petit Verdot & red & -1.729 & 28-May & 10-Sep \\
\hline 12 & Golan & 1.81 & Syra & red & -1.583 & 14-May & 13-Aug \\
\hline 13 & Golan & 1.13 & Syra & red & -1.445 & 14-May & 14-Aug \\
\hline 14 & Golan & 1.30 & Chardonnay & white & -1.340 & 29-May & 11-Sep \\
\hline 15 & Golan & 1.21 & Chardonnay & white & -1.338 & 29-May & 11-Sep \\
\hline 16 & Golan & 2.13 & Chardonnay & white & -1.556 & 29-May & 11-Sep \\
\hline 17 & Golan & 3.13 & Chardonnay & white & -1.485 & 29-May & 11-Sep \\
\hline 18 & Golan & 0.84 & Cabernet Sauvignon & red & -1.504 & 05-Jun & 03-Sep \\
\hline 19 & Golan & 1.47 & Cabernet Sauvignon & red & -1.366 & 29-May & 11-Sep \\
\hline 20 & Golan & 1.77 & Cabernet Sauvignon & red & -1.550 & 29-May & 11-Sep \\
\hline 21 & Golan & 1.36 & Pinot Gris & white & -1.463 & 29-May & 04-Sep \\
\hline 22 & Golan & 1.98 & Cabernet Sauvignon & red & -1.486 & 22-May & 07-Sep \\
\hline 23 & Golan & 2.42 & Cabernet Sauvignon & red & -1.545 & 23-May & 18-Sep \\
\hline 24 & Golan & 2.11 & Cabernet Sauvignon & red & -1.161 & 05-Jun & 07-Sep \\
\hline 25 & Golan & 2.05 & Merlot & red & -1.638 & 29-May & 18-Sep \\
\hline 26 & Golan & 1.58 & Merlot & red & -1.410 & 25-Jun & 10-Sep \\
\hline 27 & Golan & 0.96 & Merlot & red & -1.568 & 25-Jun & 07-Sep \\
\hline 28 & Golan & 3.88 & Merlot & red & -1.621 & 12-Jun & 10-Sep \\
\hline 29 & Golan & 1.17 & Petit Verdot & red & -1.258 & 13-Jun & 18-Sep \\
\hline 30 & Golan & 2.39 & Sauvignon Blanc & white & -1.511 & 19-Jun & 23-Aug \\
\hline 31 & Golan & 0.87 & Syra & red & -1.807 & 06-Jun & 05-Sep \\
\hline 32 & Golan & 0.96 & Syra & red & -1.765 & 23-May & 18-Sep \\
\hline 33 & Golan & 1.22 & Syra & red & -1.807 & 05-Jun & 31-Aug \\
\hline 34 & Golan & 3.60 & Syra & red & -1.554 & 12-Jun & 16-Aug \\
\hline 35 & Golan & 2.51 & Viognier & white & -1.368 & 15-May & 31-Aug \\
\hline 36 & Golan & 2.36 & Viognier & white & -1.520 & 15-May & 07-Sep \\
\hline 37 & Golan & 0.76 & Cabernet Sauvignon & red & -1.479 & 08-May & 11-Sep \\
\hline 38 & Golan & 2.60 & Cabernet Sauvignon & red & -1.540 & 19-May & 11-Sep \\
\hline 39 & Golan & 1.56 & Malbec & red & -1.469 & 08-May & 11-Sep \\
\hline 40 & Golan & 1.98 & Merlot & red & -1.601 & 19-May & 11-Sep \\
\hline 41 & Golan & 2.77 & Merlot & red & -1.419 & 19-May & 11-Sep \\
\hline 42 & Golan & 3.98 & Sangiovese & red & -1.581 & 19-May & 11-Sep \\
\hline 43 & Golan & 1.52 & Syra & red & -1.712 & 19-May & 11-Sep \\
\hline 44 & Golan & 1.00 & Tinta Cao & red & -1.104 & 08-May & 11-Sep \\
\hline 45 & Galilee & 2.97 & Cabernet Franc & red & -1.270 & 10-May & 18-Jul \\
\hline 46 & Galilee & 1.35 & Petit Syra & red & -1.009 & 10-May & 18-Jul \\
\hline 47 & Galilee & 2.95 & Viognier & white & -1.073 & 10-May & 18-Jul \\
\hline 48 & Galilee & 1.81 & Malbec & red & -1.151 & 10-May & 18-Jul \\
\hline 49 & Galilee & 2.99 & Chardonnay & white & -0.869 & 10-May & 18-Jul \\
\hline 50 & Galilee & 2.54 & Chardonnay & white & -1.195 & 02-May & 29-Aug \\
\hline 51 & Galilee & 2.64 & Muscat Caneli & white & -1.486 & 02-May & 29-Aug \\
\hline 52 & Galilee & 3.84 & Merlot & red & -1.431 & 02-May & 29-Aug \\
\hline 53 & Galilee & 2.87 & Viognier & white & -1.356 & 02-May & 15-Aug \\
\hline 54 & Galilee & 3.59 & Chardonnay & white & -1.441 & 02-May & 15-Aug \\
\hline
\end{tabular}


Table A1. Cont.

\begin{tabular}{|c|c|c|c|c|c|c|c|}
\hline$\#$ & Region & Size (ha) & Species & Red/White & $\Psi_{\text {stem }}(\mathrm{MPa})$ & DI Start & EOS \\
\hline 55 & Galilee & 4.81 & Roussanne & white & -1.196 & 06-Jun & 29-Aug \\
\hline 56 & Galilee & 3.67 & Cabernet Sauvignon & red & -1.594 & 06-Jun & 29-Aug \\
\hline 57 & Galilee & 4.26 & Cabernet Sauvignon & red & -1.536 & 06-Jun & 29-Aug \\
\hline 58 & Galilee & 3.35 & Gewurztraminer & white & -1.246 & 02-Jun & 15-Aug \\
\hline 59 & Galilee & 3.65 & Pinot Noir & red & -1.243 & 24-May & 16-Aug \\
\hline 60 & Galilee & 3.06 & Tannat & red & -1.528 & 24-May & 16-Aug \\
\hline 61 & Galilee & 5.46 & Cabernet Sauvignon & red & -1.770 & 24-May & 30-Aug \\
\hline 62 & Galilee & 2.43 & Cabernet Sauvignon & red & -1.611 & 24-May & 30-Aug \\
\hline 63 & Judea & 1.43 & Merlot & red & -1.989 & 15-May & 11-Sep \\
\hline 64 & Judea & 1.28 & Cabernet Sauvignon & red & -1.961 & 29-May & 11-Sep \\
\hline 65 & Judea & 1.83 & Cabernet Sauvignon & red & -1.758 & 14-May & 20-Aug \\
\hline 66 & Judea & 1.08 & Petit Verdot & red & -1.624 & 14-May & 20-Aug \\
\hline 67 & Judea & 1.23 & Syra & red & -1.826 & 14-May & 20-Aug \\
\hline 68 & Judea & 1.13 & Syra & red & -1.799 & 14-May & 20-Aug \\
\hline 69 & Judea & 0.49 & Merlot & red & -1.928 & 15-May & 28-Aug \\
\hline 70 & Judea & 0.73 & Merlot & red & -1.928 & 15-May & 28-Aug \\
\hline 71 & Judea & 2.40 & Cabernet Sauvignon & red & -1.400 & 10-May & 05-Sep \\
\hline 72 & Judea & 1.27 & Cabernet Sauvignon & red & -1.514 & 14-May & 27-Aug \\
\hline 73 & Judea & 1.27 & Cabernet Sauvignon & red & -1.566 & 14-May & 27-Aug \\
\hline 74 & Judea & 1.18 & Cabernet Sauvignon & red & -1.593 & 14-May & 27-Aug \\
\hline 75 & Judea & 0.73 & Merlot & red & -1.675 & 14-May & 13-Aug \\
\hline 76 & Judea & 0.55 & Malbec & red & -1.773 & 21-May & 27-Aug \\
\hline 77 & Judea & 0.63 & Merlot & red & -2.232 & 15-May & 28-Aug \\
\hline 78 & Judea & 0.89 & Merlot & red & -1.840 & 15-May & 28-Aug \\
\hline 79 & Judea & 1.55 & Merlot & red & -1.926 & 15-May & 28-Aug \\
\hline 80 & Judea & 2.01 & Cabernet Sauvignon & red & -1.792 & 15-May & 11-Sep \\
\hline 81 & Judea & 1.26 & Cabernet Sauvignon & red & -2.021 & 22-May & 11-Sep \\
\hline 82 & Judea & 1.39 & Cabernet Sauvignon & red & -1.928 & 15-May & 11-Sep \\
\hline
\end{tabular}

\section{References}

1. Ruiz-Sanchez, M.C.; Domingo, R.; Castel, J.R. Deficit irrigation in fruit trees and vines in Spain. Span. J. Agric. Res. 2010, 8, 5-20. [CrossRef]

2. Munitz, S.; Netzer, Y.; Schwartz, A. Sustained and regulated deficit irrigation of field-grown Merlot grapevines. Aust. J. Grape Wine Res. 2017, 23, 87-94. [CrossRef]

3. Myburgh, P.; Cornelissen, M.; Southey, T. Interpretation of Stem Water Potential Measurements. WineLand. 2016, pp. 78-80. Available online: http:/ /www.wineland.co.za/interpretation-of-stem-water-potentialmeasurements / (accessed on 15 July 2018).

4. Mulla, D.J. Twenty five years of remote sensing in precision agriculture: Key advances and remaining knowledge gaps. Biosyst. Eng. 2013, 114, 358-371. [CrossRef]

5. Gebbers, R.; Adamchuk, V.I. Precision Agriculture and Food Security. Science 2010, 327, 828-831. [CrossRef] [PubMed]

6. Matese, A.; Baraldi, R.; Berton, A.; Cesaraccio, C.; Di Gennaro, F.S.; Duce, P.; Facini, O.; Mameli, G.M.; Piga, A.; Zaldei, A. Estimation of Water Stress in Grapevines Using Proximal and Remote Sensing Methods. Remote Sens. 2018, 10, 114. [CrossRef]

7. Meron, M.; Tsipris, J.; Orlov, V.; Alchanatis, V.; Cohen, Y. Crop water stress mapping for site-specific irrigation by thermal imagery and artificial reference surfaces. Precis. Agric. 2010, 11, 148-162. [CrossRef]

8. Helman, D.; Lensky, I.M.; Tessler, N.; Osem, Y. A phenology-based method for monitoring woody and herbaceous vegetation in mediterranean forests from NDVI time series. Remote Sens. 2015, 7, 12314-12335. [CrossRef]

9. Helman, D.; Lensky, I.M.; Osem, Y.; Rohatyn, S.; Rotenberg, E.; Yakir, D. A biophysical approach using water deficit factor for daily estimations of evapotranspiration and $\mathrm{CO}_{2}$ uptake in Mediterranean environments. Biogeosciences 2017, 14, 3909-3926. [CrossRef] 
10. Helman, D.; Osem, Y.; Yakir, D.; Lensky, I.M. Relationships between climate, topography, water use and productivity in two key Mediterranean forest types with different water-use strategies. Agric. For. Meteorol. 2017, 232, 319-330. [CrossRef]

11. Helman, D.; Lensky, I.M.; Yakir, D.; Osem, Y. Forests growing under dry conditions have higher hydrological resilience to drought than do more humid forests. Glob. Chang. Biol. 2017, 23, 2801-2817. [CrossRef] [PubMed]

12. Rotbart, N.; Schmilovitch, Z.; Cohen, Y.; Alchanatis, V.; Erel, R.; Ignat, T.; Shenderey, C.; Dag, A.; Yermiyahu, U. Estimating olive leaf nitrogen concentration using visible and near-infrared spectral reflectance. Biosyst. Eng. 2013, 114, 426-434. [CrossRef]

13. Nigon, T.J.; Mulla, D.J.; Rosen, C.J.; Cohen, Y.; Alchanatis, V.; Knight, J.; Rud, R. Hyperspectral aerial imagery for detecting nitrogen stress in two potato cultivars. Comput. Electron. Agric. 2015, 112, 36-46. [CrossRef]

14. Di Gennaro, S.F.; Battiston, E.; Di Marco, S.; Facini, O.; Matese, A.; Nocentini, M.; Palliotti, A.; Mugnai, L. Unmanned Aerial Vehicle (UAV)-based remote sensing to monitor grapevine leaf stripe disease within a vineyard affected by esca complex. Phytopathol. Mediterr. 2016, 55, 262-275.

15. Mahlein, A.-K. Plant Disease Detection by Imaging Sensors-Parallels and Specific Demands for Precision Agriculture and Plant Phenotyping. Plant Dis. 2015, 100, 241-251. [CrossRef]

16. Bonfil, D.J. Wheat phenomics in the field by RapidScan: NDVI vs. NDRE. Isr. J. Plant Sci. 2017, 9978, 1-14. [CrossRef]

17. Manfreda, S.; McCabe, M.; Miller, P.; Lucas, R.; Madrigal, V.P.; Mallinis, G.; Dor, E.B.; Helman, D.; Estes, L.; Ciraolo, G.; et al. On the use of Unmanned Aerial Systems for environmental monitoring. Remote Sens. 2018, 10, 641. [CrossRef]

18. Khanal, S.; Fulton, J.; Shearer, S. An overview of current and potential applications of thermal remote sensing in precision agriculture. Comput. Electron. Agric. 2017, 139, 22-32. [CrossRef]

19. Cohen, Y.; Alchanatis, V.; Saranga, Y.; Rosenberg, O.; Sela, E.; Bosak, A. Mapping water status based on aerial thermal imagery: Comparison of methodologies for upscaling from a single leaf to commercial fields. Precis. Agric. 2017, 18, 801-822. [CrossRef]

20. Rud, R.; Cohen, Y.; Alchanatis, V.; Levi, A.; Brikman, R.; Shenderey, C.; Heuer, B.; Markovitch, T.; Dar, Z.; Rosen, C.; et al. Crop water stress index derived from multi-year ground and aerial thermal images as an indicator of potato water status. Precis. Agric. 2014, 15, 273-289. [CrossRef]

21. Jackson, R.D.; Idso, S.B.; Reginato, J.R.; Pinter, J.P. Canopy temperature as a crop water stress indicator. Water Resour. Res. 1981, 17, 1133-1138. [CrossRef]

22. Baluja, J.; Diago, M.P.; Balda, P.; Zorer, R.; Meggio, F.; Morales, F.; Tardaguila, J. Assessment of vineyard water status variability by thermal and multispectral imagery using an unmanned aerial vehicle (UAV). Irrig. Sci. 2012, 30, 511-522. [CrossRef]

23. Bellvert, J.; Zarco-Tejada, P.J.; Girona, J.; Fereres, E. Mapping crop water stress index in a 'Pinot-noir' vineyard: Comparing ground measurements with thermal remote sensing imagery from an unmanned aerial vehicle. Precis. Agric. 2014, 15, 361-376. [CrossRef]

24. Santesteban, L.G.; Di Gennaro, S.F.; Herrero-Langreo, A.; Miranda, C.; Royo, J.B.; Matese, A. High-resolution UAV-based thermal imaging to estimate the instantaneous and seasonal variability of plant water status within a vineyard. Agric. Water Manag. 2017, 183, 49-59. [CrossRef]

25. Gutiérrez, S.; Diago, M.P.; Fernández-Novales, J.; Tardaguila, J. Vineyard water status assessment using on-the-go thermal imaging and machine learning. PLoS ONE 2018, 13, e192037. [CrossRef] [PubMed]

26. Möller, M.; Alchanatis, V.; Cohen, Y.; Meron, M.; Tsipris, J.; Naor, A.; Ostrovsky, V.; Sprintsin, M.; Cohen, S. Use of thermal and visible imagery for estimating crop water status of irrigated grapevine. J. Exp. Bot. 2007, 58, 827-838. [CrossRef] [PubMed]

27. Gonzalez-Dugo, V.; Zarco-Tejada, P.; Nicolás, E.; Nortes, P. A.; Alarcón, J. J.; Intrigliolo, D. S.; Fereres, E. Using high resolution UAV thermal imagery to assess the variability in the water status of five fruit tree species within a commercial orchard. Precis. Agric. 2013, 14, 660-678. [CrossRef]

28. Espinoza, C.Z.; Khot, L.R.; Sankaran, S.; Jacoby, P.W. High Resolution Multispectral and Thermal Remote Sensing-Based Water Stress Assessment in Subsurface Irrigated Grapevines. Remote Sens. 2017, 9, 961. [CrossRef] 
29. Zarco-Tejada, P.J.; González-Dugo, V.; Williams, L.E.; Suárez, L.; Berni, J.A.J.; Goldhamer, D.; Fereres, E. A PRI-based water stress index combining structural and chlorophyll effects: Assessment using diurnal narrow-band airborne imagery and the CWSI thermal index. Remote Sens. Environ. 2013, 138, 38-50. [CrossRef]

30. Rodríguez-Pérez, J.R.; Riaño, D.; Carlisle, E.; Ustin, S.; Smart, D.R. Evaluation of hyperspectral reflectance indexes to detect grapevine water status in vineyards. Am. J. Enol. Vitic. 2007, 58, 302-317.

31. Maimaitiyiming, M.; Ghulam, A.; Bozzolo, A.; Wilkins, J.L.; Kwasniewski, M.T. Early Detection of Plant Physiological Responses to Different Levels of Water Stress Using Reflectance Spectroscopy. Remote Sens. 2017, 9, 745. [CrossRef]

32. Helman, D. Land surface phenology: What do we really 'see' from space? Sci. Total Environ. 2018, 618, 665-673. [CrossRef] [PubMed]

33. Houborg, R.; McCabe, F.M. High-Resolution NDVI from Planet's Constellation of Earth Observing Nano-Satellites: A New Data Source for Precision Agriculture. Remote Sens. 2016, 8, 768. [CrossRef]

34. Planet. Planet Satellite Imagery Products. 2018. Available online: https://www.planet.com/docs/specsheets/sat-imagery/ (accessed on 15 July 2018).

35. Munitz, S.; Netzer, Y.; Shetin, I.; Schwartz, A. Water availability dynamics have long-term effects on mature stem structure in Vitis vinifera. Am. J. Bot. 2018, 105. [CrossRef] [PubMed]

36. Netzer, Y.; Yao, C.; Shenker, M.; Bravdo, B.-A.; Schwartz, A. Water use and the development of seasonal crop coefficients for Superior Seedless grapevines trained to an open-gable trellis system. Irrig. Sci. 2009, 27, 109-120. [CrossRef]

37. Munitz, S.; Schwartz, A.; Netzer, Y. Evaluation of Seasonal Water Use and Crop Coefficients for Cabernet Sauvignon Grapevines as the Base for Skilled regulated irrigation. Acta Hortic. 2016, IV, 33-40. [CrossRef]

38. Boyer, J.S. Measuring the Water Status of Plants and Soils; Academic Press, Inc.: San Diego, CA, USA, 1995.

39. Helman, D.; Givati, A.; Lensky, I.M. Annual evapotranspiration retrieved from satellite vegetation indices for the eastern Mediterranean at $250 \mathrm{~m}$ spatial resolution. Atmos. Chem. Phys. 2015, 15, 12567-12579. [CrossRef]

40. Candiago, S.; Remondino, F.; De Giglio, M.; Dubbini, M.; Gattelli, M. Evaluating Multispectral Images and Vegetation Indices for Precision Farming Applications from UAV Images. Remote Sens. 2015, 7, 4026-4047. [CrossRef]

41. Gnyp, M.L.; Miao, Y.; Yuan, F.; Ustin, S.L.; Yu, K.; Yao, Y.; Huang, S.; Bareth, G. Hyperspectral canopy sensing of paddy rice aboveground biomass at different growth stages. Field Crops Res. 2014, 155, 42-55. [CrossRef]

42. Odi-Lara, M.; Campos, I.; Neale, M.C.; Ortega-Farías, S.; Poblete-Echeverría, C.; Balbontín, C.; Calera, A. Estimating Evapotranspiration of an Apple Orchard Using a Remote Sensing-Based Soil Water Balance. Remote Sens. 2016, 8, 253. [CrossRef]

43. Huete, A.; Didan, K.; Miura, T.; Rodriguez, E.P.; Gao, X.; Ferreira, L.G. Overview of the radiometric and biophysical performance of the MODIS vegetation indices. Remote Sens. Environ. 2002, 83, 195-213. [CrossRef]

44. Gitelson, A.A.; Buschmann, C.; Lichtenthaler, H.K. Leaf chlorophyll fluorescence corrected for re-absorption by means of absorption and reflectance measurements. J. Plant Physiol. 1998, 152, 283-296. [CrossRef]

45. Gitelson, A.A.; Merzlyak, M.N. Remote estimation of chlorophyll content in higher plant leaves. Int. J. Remote Sens. 1997, 18, 2691-2697. [CrossRef]

46. Huete, A.R. A soil-adjusted vegetation index (SAVI). Remote Sens. Environ. 1988, 25, 295-309. [CrossRef]

47. Rouse, J.W.; Haas, R.W.; Schell, J.A.; Deering, D.H.; Harlan, J.C. Monitoring the Vernal Advancement and Retrogradation (Greenwave Effect) of Natural Vegetation; NASA/GSFC: Greenbelt, MD, USA, 1974.

48. Huete, A.R.; Jackson, R.D. Soil and atmosphere influences on the spectra of partial canopies. Remote Sens. Environ. 1988, 25, 89-105. [CrossRef]

49. Planet Team. Planet Application Program Interface: In Space for Life on Earth; Planet Team: San Francisco, CA, USA, 2018. Available online: https:/ / api.planet.com (accessed on 10 September 2018).

50. Gorelick, N.; Hancher, M.; Dixon, M.; Ilyushchenko, S.; Thau, D.; Moore, R. Google Earth Engine: Planetary-scale geospatial analysis for everyone. Remote Sens. Environ. 2017, 202, 18-27. [CrossRef]

51. Verbesselt, J.; Zeileis, A.; Herold, M. Near real-time disturbance detection using satellite image time series. Remote Sens. Environ. 2012, 123, 98-108. [CrossRef]

52. Arnó, J.; Martínez Casasnovas, J.A.; Ribes Dasi, M.; Rosell, J.R. Research topics, challenges and opportunities in site-specific vineyard management. Span. J. Agric. Res. 2009, 7, 779-790. [CrossRef] 
53. Monaghan, J.M.; Daccache, A.; Vickers, L.H.; Hess, T.M.; Weatherhead, K.E.; Grove, I.G.; Knox, J.W. More 'crop per drop': Constraints and opportunities for precision irrigation in European agriculture. J. Sci. Food Agric. 2013, 93, 977-980. [CrossRef] [PubMed]

54. Gealy, D.V.; McKinley, S.; Guo, M.; Miller, L.; Vougioukas, S.; Viers, J.; Carpin, S.; Goldberg, K. DATE: A handheld co-robotic device for automated tuning of emitters to enable precision irrigation. In Proceedings of the 2016 IEEE International Conference on Automation Science and Engineering (CASE), Fort Worth, TX, USA, 21-25 August 2016; pp. 922-927.

55. Agam, N.; Segal, E.; Peeters, A.; Levi, A.; Dag, A.; Yermiyahu, U.; Ben-Gal, A. Spatial distribution of water status in irrigated olive orchards by thermal imaging. Precis. Agric. 2014, 15, 346-359. [CrossRef]

56. Netzer, Y.; Yao, C.; Shenker, M.; Cohen, S.; Bravdo, B.; Schwartz, A. Water consumtion of "superior" grapevines grown in a semiarid region. Acta Hortic. 2005, 689, 399-406. [CrossRef]

57. Chen, X.; Wang, D.; Chen, J.; Wang, C.; Shen, M. The mixed pixel effect in land surface phenology: A simulation study. Remote Sens. Environ. 2018, 211, 338-344. [CrossRef]

2018 by the authors. Licensee MDPI, Basel, Switzerland. This article is an open access article distributed under the terms and conditions of the Creative Commons Attribution (CC BY) license (http:/ / creativecommons.org/licenses/by/4.0/). 